\title{
Activation of the essential kinase PDK1 by phosphoinositide-driven trans- autophosphorylation
}

Aleksandra Levina ${ }^{1,2}$, Kaelin D. Fleming 3 , John E. Burke ${ }^{3,4}$ and Thomas A. Leonard ${ }^{1,2,5}$

${ }^{1}$ Department of Structural and Computational Biology, Max Perutz Labs, Campus Vienna Biocenter 5, 1030 Vienna, Austria

2Department of Medical Biochemistry, Medical University of Vienna, 1090 Vienna, Austria

${ }^{3}$ Department of Biochemistry and Microbiology, University of Victoria, Victoria, BC, Canada V8W 2Y2

${ }^{4}$ Department of Biochemistry and Molecular Biology, The University of British Columbia, Vancouver, British Columbia V6T 1Z3, Canada

${ }^{5}$ Correspondence: thomas.leonard@meduniwien.ac.at 


\begin{abstract}
3-phosphoinositide-dependent kinase 1 (PDK1) is an essential serine/threonine protein kinase, which plays a crucial role in cell growth and proliferation. It is often referred to as a 'master' kinase due to its ability to activate at least 23 downstream protein kinases implicated in various signaling pathways. In this study, we have elucidated the mechanism of phosphoinositide-driven PDK1 auto-activation. We show that PDK1 transautophosphorylation is mediated by a $\mathrm{PIP}_{3}$-mediated face-to-face dimer. We report regulatory motifs in the kinase-PH interdomain linker that allosterically activate PDK1 autophosphorylation via a linker-swapped dimer mechanism. Finally, we show that PDK1 is autoinhibited by its $\mathrm{PH}$ domain and that positive cooperativity of $\mathrm{PIP}_{3}$ binding drives switchlike activation of PDK1. Our work implies that the PDK1-mediated activation of effector kinases, including Akt, PKC, Sgk, S6K and RSK, many of whom are not directly regulated by phosphoinositides, is also likely to be dependent on $\mathrm{PIP}_{3}$ or $\mathrm{PI}(3,4) \mathrm{P}_{2}$.
\end{abstract}

Keywords: autoinhibition, autophosphorylation, cooperativity, HDX-MS, kinase, membrane, PDK1, PIP 3 , signaling. 


\section{Introduction}

3-phosphoinositide-dependent kinase 1 (PDK1) is a serine/threonine protein kinase that plays a central role in regulating cell growth, survival, and proliferation. Knocking out PDK1 in mice leads to early embryonic lethality (1). PDK1 overexpression has been observed in breast and ovarian tumors $(2,3)$, and its activity is increased in prion-infected neurons (4). PDK1 belongs to the AGC kinase family (which derives its nomenclature from protein kinases A, G and C) that consists of 63 members of which 23 have been reported to be PDK1 substrates, including Akt/protein kinase B (PKB), protein kinase C (PKC), p70 S6 kinase (S6K), and ribosomal S6 kinase (RSK) (5). As such, it is often referred to as a 'master kinase'. The hyperactivation of Akt, downstream of PDK1, is a hallmark of many human cancers as well as a number of rare overgrowth disorders and immune diseases $(6,7)$.

PDK1 consists of an N-terminal kinase domain and a C-terminal phosphoinositidebinding $\mathrm{PH}$ domain. The $\mathrm{PH}$ domain binds to phosphatidylinositol-3,4-bisphosphate $\left(\mathrm{PI}(3,4) \mathrm{P}_{2}\right)$ and phosphatidylinositol-3,4,5-trisphosphate (henceforth abbreviated to $\left.\mathrm{PIP}_{3}\right)$ with low nanomolar affinity (8), allowing PDK1 to be translocated to the plasma membrane upon insulin- or growth factor-stimulated $\mathrm{PIP}_{3}$ production by phosphoinositide 3-kinase (PI3K). Phosphorylation of a conserved serine (S241) in the activation loop leads to PDK1 activation. Mutation of Ser241 to alanine reduces its activity against Akt by 50 -fold while rendering it inactive against Sgk (9). Activation loop phosphorylation of PDK1 has previously been observed to occur in E. coli (9) and with purified protein in vitro (10), suggesting that PDK1 can activate itself by trans-autophosphorylation. Consistent with these observations, PDK1 dimerization has been reported in cells $(11,12)$ and PH domain-mediated dimerization has been reconstituted on $\mathrm{PIP}_{3}$-containing lipid bilayers (13). However, the 
molecular mechanisms of lipid-mediated activation by dimerization and transautophosphorylation remain poorly understood.

Whether PDK1 activation is regulated at all remains controversial. Studies performed on overexpressed PDK1 in different cell lines have reported contradictory results. Some have reported no or minor changes in PDK1 localization in response to insulin $(8,14)$ whereas others have reported insulin-dependent membrane translocation (15) and growth-factor dependent PDK1 activation (12). High levels of PDK1 activation loop (S241) phosphorylation that are not affected by insulin stimulation are often observed in PDK1 overexpressed cells (16-18). However, S241 phosphorylation of endogenous PDK1 has been shown to be insulindependent in a mouse hypothalamic cell line (19). These contradictions highlight the difficulties of studying signaling events in cells under conditions of ectopic over-expression, cell population response heterogeneity, and the transient nature of the events themselves. Nevertheless, these observations have led many to conclude that PDK1 is constitutively active in cells and that signal propagation is regulated by a variety of mechanisms at the level of its substrates, including co-localization, allosteric activation, or post-translational modification. These mechanisms, however, beg the question of why PDK1 is regulated by activation loop phosphorylation at all. Moreover, the presence of a constitutively active kinase in cells is likely to lead to spurious off-target phosphorylation events, uncoupled from growth factor signaling, that are incompatible with the coordination of cellular events in a tightly regulated manner in both space and time.

These contradictions prompted us to address the question of how PDK1 activity is regulated at a molecular level. We show that PDK1 activation by trans-autophosphorylation is dependent on a specific face-to-face dimer mediated by its $\alpha G$ helix. Trans- 
autophosphorylation is further enhanced by two previously uncharacterized motifs in the kinase-PH interdomain linker of PDK1. Finally, we show that PDK1 exists in an autoinhibited conformation in the absence of $\mathrm{PIP}_{3}$ or $\mathrm{PI}(3,4) \mathrm{P}_{2}$, irrespective of its phosphorylation state. We propose a model of lipid-dependent PDK1 activation in which PH domain-mediated autoinhibition is relieved by $\mathrm{PIP}_{3}$ or $\mathrm{PI}(3,4) \mathrm{P}_{2}$ binding, leading to kinase domain dimerization and trans-autophosphorylation at the membrane. Our findings suggest that PDK1 activation and activity, as well as the activation of 23 downstream kinases, themselves PDK1 substrates, are restricted to $\mathrm{PIP}_{3}$ or $\mathrm{PI}(3,4) \mathrm{P}_{2}$-containing membranes.

\section{Results}

\section{A transient but specific dimer controls PDK1 autophosphorylation}

To investigate the mechanism of PDK1 autoactivation, we first sought to establish suitable construct boundaries of the PDK1 kinase domain that would permit a systematic and quantitative analysis of activation loop autophosphorylation. All constructs employed in this study are defined in Supplementary Table 1 and intact mass spectra for all recombinant proteins are provided in Supplementary Figures 1-2. Chordates encode a region of 50 amino acids immediately upstream of an alternative splice site that is not conserved or missing in older PDK1 orthologs. This region is predicted to be intrinsically disordered and its function has not been investigated. It is not present in isoform 2 of human PDK1. The reported PDK1 kinase domain comprising residues 51-359 (UniProt 015530-2) exhibited autophosphorylation of a second residue with low efficiency in an in vitro kinase assay (Supplementary Figure 1A). Since residues 51-71 are disordered in crystal structures of the PDK1 kinase domain, we truncated the N-terminus to create a construct comprising residues 
73-359 (Figure 1A) that undergoes stoichiometric activation loop phosphorylation in vitro (Supplementary Figure 1B-D). Henceforth, we refer to this construct as PDK1 ${ }^{\text {SKD }}$ (short kinase domain, where 'short' in this context refers to the C-terminal boundary of the construct).

Both the short kinase domain (PDK1 ${ }^{\mathrm{SKD}}$ ) and near full-length PDK1 (PDK1 ${ }^{\mathrm{FL}}$ ) are monomeric in solution as observed by size exclusion chromatography coupled to multi-angle light scattering (SEC-MALS) (Fig. 1B) at a concentration $(2 \mu \mathrm{M})$ three orders of magnitude higher than that reported in cells (20), consistent with expectations for a transient interaction. We therefore modeled the PDK1 kinase domain dimer using the ROSETTA symmetric modeling tool (21) using the crystal structure of the monomeric kinase domain (PDB code 2biy). Since the conformation of the activation loop in the context of the dimer is unknown, we deleted the corresponding residues 228-245 from the monomer structure for the purposes of modeling. The best scoring model exhibited a face-to-face arrangement of the two protomers (Fig. 1C) in which the surface of interaction is highly conserved and partially hydrophobic in nature (Supplementary Figure 3A). Strikingly, the dimer model is superimposable with crystal structures of MEK1 and MEK2 dimers (Supplementary Figure 3B), as well as the B-RAF:MEK1 complex (Supplementary Figure 3C), in which the $\alpha \mathrm{G}$ helix is found in the dimerization interface. Independent modeling of the kinase domain dimer with AlphaFold2, which employs a deep learning neural network algorithm to combine evolutionary information with known physical and stereochemical constraints $(22,23)$, resulted in an essentially identical arrangement of the two protomers, with a root mean square deviation (r.m.s.d.) of 1.87-2.73 $\AA$ over all backbone $\mathrm{C}_{\alpha}$ atoms of both chains for ten models generated with and without template matching (Supplementary Figure 3D). 
In the PDK1 dimer, an invariant tyrosine or phenylalanine (human Y288, Supplementary Figure 4A) is contributed to the interface by the $\alpha \mathrm{G}$ helix of each protomer (Fig. 1C). Reported substrate kinases of PDK1 that do not undergo autophosphorylation do not exhibit conservation at this position in their $\alpha \mathrm{G}$ helices (Supplementary Figure 4B). Therefore, to test our in silico model in vitro, we mutated Y288 to either alanine (PDK1 SKD Y288A, Supplementary Figure 1E), thereby removing the side chain, or glutamate (PDK1 ${ }^{\mathrm{SKD}}$ Y288E, Supplementary Figure 1F), thereby creating a charge repulsion in the interface. The dimerization of wild-type and mutant kinase domains was evaluated with a radiometric autophosphorylation assay using labeled $\left[\gamma^{-32} \mathrm{P}\right]$ ATP. Mutation of Y288 to either alanine or glutamate resulted in complete abrogation of autophosphorylation under assay conditions in which the wild-type kinase domain is stoichiometrically phosphorylated on S241 (Fig. 1D, Supplementary Figure 1D). It is worth noting that expression of both PDK1 ${ }^{\text {SKD }}$ Y288A and PDK1 ${ }^{\text {SKD }}$ Y288E with an N-terminal dimeric GST-tag in insect cells resulted in stoichiometrically monophosphorylated proteins (Supplementary Figure 1G), indicating that mutation of Y288 does not completely abrogate autophosphorylation and can be overcome by artificial dimerization. Moreover, the crystal structure of the kinase domain of PDK1 bearing a Y288G mutation designed to disrupt lattice contacts (24) (Supplementary Figure 4C) illustrates that mutation of Y288 does not result in any conformational changes in the kinase domain. Together, these results indicate that PDK1 autophosphorylation is dependent on a specific kinase domain dimer centered on Y288. 


\section{PIF pocket occupancy promotes PDK1 trans-autophosphorylation}

Typical AGC kinase domains contain a hydrophobic pocket in the $\mathrm{N}$ lobe and a long Cterminal tail containing multiple regulatory motifs, including a hydrophobic motif (HM) with the sequence $\phi X X \phi$, where $\phi=$ hydrophobic amino acid and X = any amino acid (25). Docking of the HM into the hydrophobic pocket promotes the active conformation of the kinase domain and its mutation is associated with reduced kinase activity (26-29). Some, but not all, AGC kinases also possess a regulatory phosphorylation site immediately C-terminal to the HM. AGC kinases with phosphorylatable HMs or with glutamate substitutions, including Akt, PKC, RSK, S6K, and SGK, are reported substrates of PDK1 (5). Phosphorylation of the HM of these substrate kinases is reported to drive association with the hydrophobic pocket of PDK1 and consequent activation loop phosphorylation of these substrates (10, 30-35).

In contrast to other members of the AGC kinase family, PDK1 does not contain a canonical C-terminal tail. Instead, the kinase domain is followed by a flexible linker and a Cterminal membrane-binding PH domain. Nevertheless, binding of a HM peptide to the hydrophobic pocket of PDK1 leads to conformational changes resulting in higher ATP binding affinity (36) and increased overall stability of the kinase domain $(30,37)$. The prevailing model of substrate phosphorylation by PDK1 therefore suggests that the phosphorylated HM of the substrate binds into the hydrophobic pocket of PDK1 and allosterically activates PDK1 against the docked substrate. However, binding of a HM peptide to the hydrophobic pocket has also been shown to promote PDK1 autophosphorylation (10). We therefore reasoned that PDK1 auto-activation likely depends on a functional HM. 
To test whether a functional HM is necessary for kinase domain dimerization and autophosphorylation, we fused PIFtide, a peptide derived from the HM of PRK2 (QEMFRDFDYIADWC) that binds to PDK1 with low nanomolar affinity (38), to the Nterminus of the kinase domain (PDK1 ${ }^{\text {PIF-SKD }}$, Supplementary Figure $1 \mathrm{H}$ ). The N-terminus (Q73) is just $8 \AA$ away from the end of the PIFtide sequence (PDB 4RRV), which could be bridged with a simple poly-Gly $\left(\mathrm{G}_{5}\right)$ linker (Fig. 2A). This construct design ensured constitutive binding of the peptide to the hydrophobic pocket. To avoid autophosphorylation in the presence of ATP, which might disrupt dimerization, we introduced a S241A mutation (Supplementary Figure 1I). Whilst SEC-MALS revealed PDK1 ${ }^{\text {PIF-SKD }}$ S241A to be monomeric, even in the presence of ATP (Fig. 2B), fusion of PIFtide to wild-type PDK1 ${ }^{\text {SKD }}$ resulted in faster auto-phosphorylation kinetics (Fig. 2C), confirming that occupancy of its hydrophobic pocket promotes PDK1 autophosphorylation.

In order to obtain a stable kinase domain dimer amenable to structural and biophysical analysis, we next fused the PIFtide sequence to the C-terminus of the kinase domain (PDK1 1 SKD-PIF) (Fig. 2A). Our in silico model of the kinase domain dimer revealed that the C-terminus of the kinase domain and the first residue of a HM peptide (modeled using PDB 4RRV) docked in the hydrophobic pocket of the opposing protomer were just $29.4 \AA$ apart. We therefore designed a minimal poly Gly-Ser (GS) ${ }_{4}$ linker that would allow the Cterminal PIFtide to reach into the hydrophobic pocket of the other protomer. We hypothesized that, provided that the linker length is sufficient, the high affinity of the PIFtide towards the hydrophobic pocket should result in its constitutive binding and lead to stable

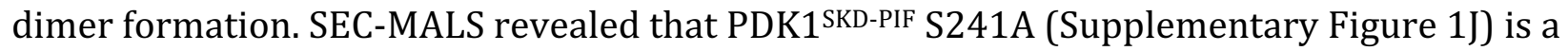
constitutive dimer in both the absence and presence of ATP (Fig. 2B). The presence of ATP 
resulted in a noticeable reduction in the hydrodynamic radius of PDK1 ${ }^{\text {SKD-PIF, }}$, consistent with the specific organization of the two activation loops in the center of the dimer and a consequent compaction of the particle.

The PDK1 1 SKD-PIF dimer was then used to analyze the conformational changes associated with dimer formation by crosslinking coupled to mass spectrometry (XL-MS) using the zero-length, heterobifunctional crosslinker 1-ethyl-3-(3dimethylaminopropyl)carbodiimide hydrochloride (EDC). We determined dimer- and monomer-specific crosslinks and mapped the crosslinks onto the dimer model (Fig. 2D). In the dimer, we observed 36 novel cross-links between residues in the C-terminal PIFtide sequence and residues in the N-terminus of PDK1 (Supplementary Table 2) consistent with a face-to-face dimer formed by exchange of the C-terminal PIFtide motifs. We also observed striking changes within the activation loop. 51 out of 53 crosslinks in the monomer that were formed between the activation loop and either the $\mathrm{N}$ lobe (glycine-rich loop and $\alpha \mathrm{B}$ helix) or C lobe ( $\alpha \mathrm{G}$ and $\alpha \mathrm{H}$ helices) as well as a specific cross-link in the catalytic loop of the kinase domain were not present in the dimer (Supplementary Table 3). This result is consistent with the activation loop being highly flexible when not phosphorylated and suggests that it adopts a different conformation in the dimer, which is presumably permissive for transautophosphorylation.

Further structural details were obtained by hydrogen-deuterium exchange-mass spectrometry (HDX-MS). HDX-MS reports on the solvent accessibility of backbone amide hydrogens, thereby permitting the mapping of conformational changes. We compared the dimeric PDK1 $1^{\text {SKD-PIF }}$ to monomeric PDK1 ${ }^{\text {SKD }}$ and mapped the differences in deuterium 
incorporation onto the dimer model (Fig. 2E-H, Supplementary Figure 5A). In the N-lobe, the largest decrease in exchange is observed around the hydrophobic pocket $\alpha \mathrm{C}$ and $\alpha \mathrm{B}$ helixes), confirming binding of the PIFtide. Neighboring regions, as well as the ATP binding pocket, catalytic loop, and activation loop, are also protected in the dimer, reflecting conformational changes due to PIFtide-induced dimerization. Curiously, we did not observe any changes in the $\alpha \mathrm{G}$ helix associated with dimerization, which most likely reflects the fact that there are no secondary structure changes in the $\alpha \mathrm{G}$ helix upon dimerization. Finally, we observed deprotection of the $\alpha \mathrm{H}-\alpha \mathrm{I}$ loop in PDK1 $1^{\text {SKD-PIF }}$ suggesting that specific interactions present in the monomeric kinase domain are lost upon dimerization (Fig. 2H, yellow). Superimposition of the activation loop from the structure of PDK1 bearing a S241 to alanine mutation (Fig. $2 \mathrm{H}$, red), revealed that the tip of the activation loop contacts the deprotected region, an observation that is consistent with our XL-MS data and confirms a conformational change of the activation loop during dimerization, an event which is a prerequisite for transautophosphorylation.

In conclusion, PDK1 autophosphorylation is promoted by occupancy of its hydrophobic pocket, and kinase domain dimerization leads to remodeling of the activation loop for trans-autophosphorylation.

\section{PDK1 encodes a hydrophobic motif that drives trans-autophosphorylation}

Since PDK1 autophosphorylation is promoted by binding of PIFtide to its hydrophobic pocket, we next questioned the source of the HM in the autophosphorylation reaction. Sequence alignment of PDK1 orthologs revealed strong conservation in the flexible linker 
between the kinase and the PH domains (residues 359-389), which was especially pronounced within chordates (Fig. 3A, Supplementary Figure 6A). We therefore tested whether this sequence influences autophosphorylation by comparing the kinetics of PDK1 ${ }^{\text {SKD }}$ (residues 73-359, encompassing just the kinase domain) with a construct of PDK1 comprising an additional 30 amino acids containing the kinase-PH interdomain linker sequence, which we henceforth refer to as PDK1 long kinase domain (PDK1 ${ }^{\text {LKD }}$, residues 73389; Supplementary Figure 1K-L). PDK1 LKD autophosphorylation kinetics were dramatically faster than PDK1 ${ }^{\mathrm{SKD}}$ (Fig. 3B) indicating that the 30 amino acids C-terminal to the kinase domain promote autophosphorylation. However, the linker did not affect the oligomeric state of PDK1 LKD S241A (Supplementary Figure 1M), which remained monomeric at $5 \mu \mathrm{M}$ even in the presence of $1 \mathrm{mM}$ ATP (Fig. 3C).

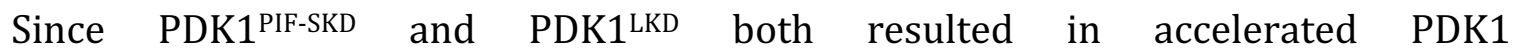
autophosphorylation kinetics, we hypothesized that the kinase-PH linker might contain a previously unidentified HM that could bind into the hydrophobic pocket of the opposing protomer in the dimer. We reasoned, that, if this was the case, fusion of PIFtide to the Nterminus of PDK1 ${ }^{\text {LKD }}$ (PDK1 ${ }^{\text {PIF-LKD) }}$ would compete with the linker for binding to the hydrophobic pocket, thereby inhibiting stimulation of PDK1 autophosphorylation by the linker. To test this hypothesis, we compared the autophosphorylation kinetics of PDK1 PIF-LKD

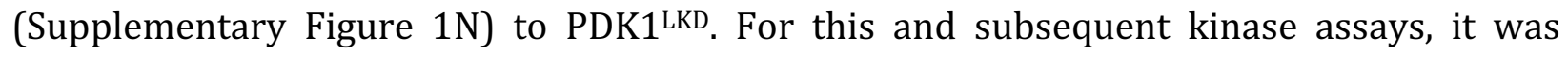
necessary to adjust the reaction conditions in order to slow the rate of PDK1 LKD autophosphorylation sufficiently to obtain high quality kinetic data. This was achieved by reducing the ATP concentration from $200 \mu \mathrm{M}$ to $50 \mu \mathrm{M}$ and PDK1 concentration from $5 \mu \mathrm{M}$ to $1 \mu \mathrm{M}$. PDK1 ${ }^{\text {PIF-LKD }}$ exhibited reduced autophosphorylation kinetics (Fig. 3D), suggesting 
that the PIFtide sequence competes with the kinase-PH linker for binding to the hydrophobic pocket and indicating that PDK1 encodes a bona fide HM in its linker.

We next sought to identify a putative HM sequence in the linker. The linker sequence contains several patches of hydrophobic residues, but only one corresponds to a typical HM motif ( ${ }^{383}$ Phe-Gly-Cys-Met ${ }^{386}$ ) and is capable of reaching into the hydrophobic pocket of the opposing protomer in our in silico model. The sequence of this motif aligns favorably with the structurally validated HMs of 57 out of 62 other AGC kinases (Supplementary Figure 6B). Mutation of both of these hydrophobic residues to alanines (PDK1 ${ }^{\text {LKD }}$ F383A/M386A, Supplementary Figure 10) completely abrogated the effect of the linker (Fig. 3E), confirming that the linker contains a HM that binds to the hydrophobic pocket and acts as an allosteric modulator.

However, the increased autophosphorylation kinetics of PDK1 ${ }^{\mathrm{LKD}}$ compared to PDK1 PIF-SKD (Fig. 3D) suggested that the HM is not the only part of the linker that promotes autophosphorylation. A conserved Asn-Phe-Asp (NFD) motif in the C-terminal tail of AGC kinases PKC iota and PKA has been shown to be important for the binding of ATP and consequently, for kinase activity $(39,40)$. Within the PDK1 linker sequence, we observed an Asn-Tyr-Asp (NYD) motif five residues N-terminal to the HM. Mutation of Y376 to alanine (PDK1 LKD Y376A, Supplementary Figure 2A) resulted in slower autophosphorylation kinetics than the wild-type long kinase domain (PDK1 ${ }^{\mathrm{LKD}}$ ) (Fig. 3F) indicating that the NYD motif also promotes PDK1 autophosphorylation.

Taken together, these results suggest that the linker between the kinase and PH domains encodes previously unidentified, but equivalent, NFD and HM motifs found in the 
C-terminal tail of other AGC kinases. We conclude that PDK1 autophosphorylation is allosterically regulated by its kinase-PH interdomain linker in a mechanism analogous to a domain-swap.

\section{PDK1 is autoinhibited by its PH domain}

A C-terminal membrane binding $\mathrm{PH}$ domain that binds to $\mathrm{PI}(3,4) \mathrm{P}_{2}$ and $\mathrm{PIP}_{3}$ with high affinity allows PDK1 to be targeted to membranes in response to growth factor signaling (8). PI3K-dependent plasma membrane translocation and a consequent increase in PDK1 dimerization have previously been observed in cells (11). Based on this, we hypothesized that PDK1 auto-activation might be restricted to $\mathrm{PIP}_{3}$ and $\mathrm{PI}(3,4) \mathrm{P}_{2}$-containing membranes. Such a mechanism of membrane-restricted kinase activity has previously been observed in the related AGC kinases Akt and Sgk3, which contain a $\mathrm{PIP}_{3}$ - and $\mathrm{PI}(3,4) \mathrm{P}_{2}$-binding $\mathrm{PH}$ domain or PI3P-binding PX domain respectively (41-43) (Truebestein et al., article in press, PNAS 2021). In its inactive state, the catalytic cleft of Akt is occluded by its PH domain, an autoinhibitory interaction which is relieved by $\mathrm{PIP}_{3}$ or $\mathrm{PI}(3,4) \mathrm{P}_{2}$ binding $(42,44)$ (Truebestein et al., article in press, PNAS 2021). We therefore hypothesized that PDK1 activation might be regulated in a similar way.

To test whether the PH domain inhibits PDK1 autophosphorylation, we compared the autophosphorylation kinetics of near full-length PDK1 containing its PH domain (residues 73-560; PDK1 ${ }^{\mathrm{FL}}$, Supplementary Figure 2B-C) to PDK1 ${ }^{\mathrm{LKD}}$ and PDK1 ${ }^{\mathrm{SKD}}$ (Fig. 4A). The autophosphorylation kinetics of PDK1 ${ }^{\mathrm{FL}}$ were significantly slower than PDK1 ${ }^{\mathrm{LKD}}$, suggesting that the PH domain exerts an inhibitory effect on the kinase domain. It is worth noting that the inhibitory effect of the PH domain could only be observed by comparing PDK1 ${ }^{\mathrm{FL}}$ with 
PDK1 ${ }^{\mathrm{LKD}}$, since PDK1 ${ }^{\mathrm{SKD}}$ does not contain the regulatory NYD or HM motifs provided by the kinase-PH linker. Comparison of PDK1 ${ }^{\text {SKD }}$ with PDK1 $1^{\mathrm{FL}}$ would lead to the erroneous conclusion that the PH domain activates PDK1.

We next sought to investigate the mechanism and structural basis of PH domainmediated autoinhibition by HDX-MS. We compared the deuterium incorporation kinetics for the kinase (PDK1 ${ }^{\mathrm{SKD}}$ ) and PH (PDK1 ${ }^{\mathrm{PH}}$, Supplementary Figure 2D) domains of PDK1 with fulllength PDK1 (PDK1 ${ }^{\mathrm{FL}}$ ) in pairwise HDX-MS experiments. Comparison of PDK1 ${ }^{\mathrm{FL}}$ with PDK1 ${ }^{\text {SKD }}$ revealed a large area of deprotection on one side of the kinase domain in the absence of the PH domain (Fig. 4B, Supplementary Figure 7A). The putative PH domain binding interface covers the whole of the catalytic cleft, including the substrate-binding helix $\alpha \mathrm{D}$, as well as the $\alpha \mathrm{G}$-containing dimerization surface, suggesting that the $\mathrm{PH}$ domain mediates PDK1 autoinhibition by impairing dimerization and trans-autophosphorylation as well as downstream substrate engagement. To further confirm the interaction between the two domains, we compared PDK1 ${ }^{\mathrm{FL}}$ to the isolated $\mathrm{PH}$ domain (PDK1 ${ }^{\mathrm{PH}}$ ). In the absence of the kinase domain, a large part of the $\mathrm{PH}$ domain, including the $\mathrm{PIP}_{3}$ binding pocket, shows increased H/D exchange (Fig. 4C, Supplementary Figure 7B), suggesting that the PH domain engages in an intramolecular interaction with the kinase domain in full-length PDK1. This surface is highly conserved (Supplementary Figure 7C) and covers the positively charged phosphoinositide binding pocket (Supplementary Figure 7D), but does not include the highly divergent N-bud extension that is peculiar to the PH domain of PDK1 (Supplementary Figure 7E). 
We observed in the HDX-MS data that the surface of the PH domain including the phosphoinositide binding pocket exhibited lower rates of hydrogen-deuterium exchange in full-length PDK1 compared to the isolated PH domain (Supplementary Figure 8A-F). This implied that the binding pocket may be sequestered in the autoinhibitory interface between the kinase and PH domains. This property of lipid-regulated kinases has previously been observed for Akt (41), Sgk3 (43), PKC $(45,46)$ and PKD (47). To test this hypothesis, we performed a liposome pelleting assay in which we compared the binding affinities of fulllength PDK1 with its isolated PH domain. We observed that the PH domain bound to $\mathrm{PIP}_{3}$ containing liposomes with approximately 2-fold higher affinity than full-length PDK1 (Figure 4D). The binding of the isolated PH domain could not be fit with a one-site binding model, but exhibited positive cooperativity (Hill coefficient $=1.91$ ), consistent with dimerization of the $\mathrm{PH}$ domain on the membrane, as has previously been reported (13). PDK1 ${ }^{\mathrm{FL}}$ exhibited sigmoidal binding with a Hill coefficient of 6.01. This strong positive cooperativity likely reflects additional interactions that stabilize the $\mathrm{PIP}_{3}$-bound conformation, including kinase domain dimerization and HM exchange (Figure 4E).

Such an interaction between the PH and the kinase domain should be reflected in the overall dimensions of PDK1. We therefore analyzed the conformation of PDK1FL in solution by small-angle X-ray scattering (SAXS) (Fig. 4F-K). We compared PDK1 ${ }^{\mathrm{FL}}$ to the previously determined dimensions of Akt, since both proteins have almost identical molecular weights (57 and $56 \mathrm{kDa}$ respectively) and domain compositions. The calculated radius of gyration $\left(\mathrm{R}_{\mathrm{g}}=29.3 \AA\right)$ and maximum dimension $\left(\mathrm{D}_{\max }=82.9 \AA\right)$ of PDK1 ${ }^{\mathrm{FL}}$ are closer to the ones obtained for Akt in the autoinhibited state $\left(R_{g}=27 \AA\right.$ and $\left.D_{\max }=97 \AA\right)$ than for an interface mutant of Akt that adopts an open, $\mathrm{PIP}_{3}$-independent, conformation $\left(\mathrm{R}_{\mathrm{g}}=32 \AA\right.$ 跬 $\mathrm{D}_{\max }=122$ 
Å) (42). Furthermore, the overall dimensions of PDK1 $1^{\mathrm{FL}}$ were not affected by activation loop (S241) phosphorylation, demonstrating that PDK1 is autoinhibited even when stoichiometrically phosphorylated. These observations imply that PH domain-mediated autoinhibition could restrict both PDK1 trans-autophosphorylation and activity against downstream substrates to membranes enriched in either $\mathrm{PIP}_{3}$ or $\mathrm{PI}(3,4) \mathrm{P}_{2}$.

\section{Discussion}

Our work describes hereto unknown molecular mechanisms of PDK1 activation. In contrast to previous assumptions that PDK1 is constitutively active in cells, we propose a model in which PDK1 auto-activation and subsequent substrate phosphorylation are restricted to $\mathrm{PI}(3,4) \mathrm{P}_{2}$ and $\mathrm{PIP}_{3}$-containing membranes (Fig. 5). Prior to pathway activation by insulin or growth factors, PDK1 is present in the cytoplasm in an autoinhibited conformation in which the substrate binding cleft and the dimerization surface of the kinase domain, as well as the lipid binding site of the PH domain, are sequestered in an intramolecular interaction. Upon $\mathrm{PI}(3,4) \mathrm{P}_{3}$ or $\mathrm{PI}(3,4) \mathrm{P}_{2}$ production in the membrane, $\mathrm{PDK} 1$ is recruited via its $\mathrm{PH}$ domain, which binds specifically to either lipid, thereby breaking the autoinhibitory interaction. Endogenous PDK1 concentrations have been reported to be approximately $30 \mathrm{nM}$ (20), a concentration at which we do not observe any dimer formation in vitro. Lipid-mediated recruitment to the membrane results in local concentration of PDK1, which presumably drives kinase domain dimerization. The linker-swap ensures the specificity of PDK1 dimerization and allosterically promotes trans-autophosphorylation via a previously uncharacterized HM. Upon autophosphorylation, the kinase domains of PDK1 dissociate to 
permit downstream substrate phosphorylation. Whether autophosphorylation drives the dissociation of the kinase domains or dimerization is sufficiently transient that a dedicated mechanism of dissociation is not required, however, remains an open question.

PDK1 dimerization and trans-autophosphorylation have been previously reported $(10,11,18)$. Masters et al, however, have proposed a model of the PDK1 kinase domain dimer (11) that is quite different to the model proposed here. Our biochemical and structural modeling show that the HM we have identified in the kinase-PH inter-domain linker can reach into the hydrophobic pocket of the other protomer in the dimer. In the model proposed by Masters et al, the $\alpha \mathrm{G}$ helix of one protomer interacts with the hydrophobic pocket of the other protomer. The hydrophobic pockets in this dimer are therefore oriented in a way that is incompatible with the binding of the HM from the opposing protomer. Although our structural model is derived from in silico docking of an existing crystal structure, evidence for this mode of kinase domain dimerization is supported by crystal structures of MEK1 and MEK2 homodimers as well as the BRAF:MEK1 heterodimer, all of which are arranged in a face-to-face arrangement that is superimposable with our model of PDK1. Furthermore, the relevance of $\alpha \mathrm{G}$-mediated heterodimerization in B-Raf:MEK signaling is well established (48, 49). $\alpha \mathrm{G}$ helix-mediated homodimerization of PDK1 is, however, dependent on $\mathrm{PIP}_{3}$ or $\mathrm{PI}(3,4) \mathrm{P}_{2}$, since the $\mathrm{PH}$ domain obscures the dimerization surface of the kinase domain in the absence of lipids. The same surface of other kinases has been observed to mediate myriad protein-protein interactions that control (auto)inhibition $(42,44,50,51)$, substrate docking (52), recruitment of phosphatases (53), and homo- and heterodimerization-driven transautophosphorylation (48). 
The PH domain has previously been proposed to regulate PDK1 kinase domain dimerization $(11,13,18)$. These studies propose a model in which PDK1 forms an autoinhibitory dimer in the cytoplasm that is dissociated upon trans-autophosphorylation of $\mathrm{T} 513$ in the $\mathrm{PH}$ domain following the binding of $\mathrm{PDK} 1$ to $\mathrm{PIP}_{3}$ or $\mathrm{PI}(3,4) \mathrm{P}_{2}$ in the membrane. It is unclear, however, what would drive PDK1 dimerization in the cytoplasm considering low nanomolar PDK1 expression levels and the fact that dimerization cannot be observed up to $2 \mu \mathrm{M}$ in vitro. Moreover, we did not observe any T513 phosphorylation in full-length PDK1 following stoichiometric activation loop phosphorylation (Supplementary Figure 2C). Our HDX-MS analysis, however, revealed that T513 is located within the intramolecular interface between the PH and kinase domains. Comparison of the rates of deuterium incorporation for the peptide comprising residues 511-515 of PDK1 shows that the rate of deuterium incorporation is significantly higher in the absence of the kinase domain (Supplementary Figure 8F). This was, in fact, the largest difference in deuterium incorporation observed over the whole protein. We therefore hypothesize that the insulinand growth factor-independent activity of PDK1 T513E previously observed in cells $(11,54)$ may be due to disruption of the autoinhibitory interaction between the kinase and PH domains. In this respect, it is also worth noting that T513 is invariant in chordate PDK1 orthologs. However, though we doubt the physiological role of T513 phosphorylation, PH domain-mediated dimerization of PDK1 on membranes (13) is very much substantiated by the cooperative binding of the $\mathrm{PH}$ domain to $\mathrm{PIP}_{3}$-containing liposomes. This mechanism enhances the specificity of PDK1 dimerization and, together with intramolecular sequestration of both the $\mathrm{PIP}_{3}$ binding site and the dimerization surfaces of the $\mathrm{PH}$ and kinase domains, ensures high positive cooperativity in $\mathrm{PIP}_{3}$ sensing, leading to switch-like 
behavior in PDK1 activation. Although the affinities of PDK1 for $\mathrm{PIP}_{3}$ and $\mathrm{PI}(3,4) \mathrm{P}_{2}$ were previously reported to be 1.6 and $5.2 \mathrm{nM}$ respectively (8), it should be noted that these experiments were performed with GST-tagged PDK1. As such, the discrepancy between the reported binding affinities and the values of 3.5-6.5 $\mu \mathrm{M}$ that we have measured is likely attributable to an avidity effect that arises from the use of a dimeric fusion tag. Interestingly, the binding affinity of PDK1 ${ }^{\mathrm{FL}}$ for $\mathrm{PIP}_{3}$-containing liposomes is only marginally higher than the 15-20 $\mu \mathrm{M}$ determined for Akt1 binding to liposomes of identical composition (41).

The PH domain of PDK1 is essential for PDK1 activity. Abrogation of $\mathrm{PIP}_{3}$ binding by mutagenesis of arginines 472,473 and 474 to leucine leads to embryonic lethality in mice as a consequence of the inability of PDK1 to bind $\mathrm{PIP}_{3}$ or $\mathrm{PI}(3,4) \mathrm{P}_{2}$ (55). However, introduction of a single point mutation, K465E, that disrupts $\mathrm{PIP}_{3}$ binding did not completely abrogate PDK1 substrate phosphorylation, despite leading to impaired mouse development (56). Our analysis of $\mathrm{PIP}_{3}$ binding in full-length PDK1 indicates that the $\mathrm{PIP}_{3}$ binding site is obscured, an observation corroborated by HDX-MS analysis of the intramolecular interface. In fact, peptides containing K465 exhibit significantly increased rates of deuterium incorporation in the absence of the kinase domain (Supplementary Figures 7B, 8A-B). These observations suggest that this mutation might also destabilize the autoinhibitory interaction between the PH and the kinase domains, potentially explaining the residual PDK1 activity and viability observed.

We have identified uncharacterized NFD and HMs in the interdomain linker of PDK1 that are equivalent to those found in the C-terminal tail of all other AGC kinases and that allosterically regulate PDK1 activity. Previously, PDK1 was thought to lack the canonical C- 
terminal extension to its kinase domain. While the fact that the HM sequence in PDK1 is only conserved in chordates raises questions about the mechanism of PDK1 activation in evolutionarily older species, we cannot discount that sequence alignments are not powerful enough to identify an analogous sequence in these species. We show that the HM within the interdomain linker binds to the hydrophobic pocket of PDK1 during transautophosphorylation. This interaction, while dramatically stimulating autophosphorylation, is necessarily of low affinity compared to the high affinity interaction of PIFtide, since the kinase domain dimer of PDK1 must be capable of dissociation post-activation loop autophosphorylation in order to engage its substrates. This explains why PKD1 ${ }^{\mathrm{LKD}}$ is

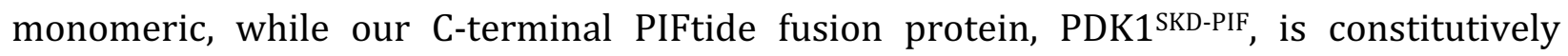
dimeric. Mutation of the central residue in the PDK1 hydrophobic pocket (L155E) was previously shown to result in early embryonic lethality in mice (55). To date, the hydrophobic pocket in PDK1 has been reported to facilitate the interaction with its substrates. However, our findings indicate that the hydrophobic pocket plays an important role in PDK1 auto-activation, which may explain the strong phenotype observed.

The kinase-PH interdomain linker has previously been reported to mediate PDK1 translocation to the nucleus following insulin stimulation $(17,57)$. The authors of this study identified a putative nuclear export signal (NES) in mouse PDK1 that overlaps with the HM we have identified in this study. However, data from this study also indicates that the nuclear-cytoplasmic distribution of PDK1 is unaltered in cells lacking PTEN, where PI3K signaling is dramatically up-regulated. Whilst we cannot discount the presence of a NES in the interdomain linker, the activation of a nuclear pool of PDK1 would require actively signaling pools of $\mathrm{PIP}_{3}$ or $\mathrm{PI}(3,4) \mathrm{P}_{2}$. Though some evidence has hinted at their existence $(58)$, 
further work is undoubtedly required to probe whether the PI3K pathway is physiologically relevant in the nucleus.

A striking difference between the PDK1 interdomain linker and the C-terminal tail of PDK1 substrates is the absence of a phosphorylated turn motif. The turn motif, reported to be co-translationally phosphorylated by mTORC2 (59), binds to a conserved basic patch on the surface of the $\mathrm{N}$-lobe ( $\beta 1$ and $\beta 2$ ) of the kinase domain, and is important for regulating the stability of both Akt and PKC (60). In our model of the trans-autophosphorylating PDK1 kinase domain dimer, the N-lobe surface to which the phosphorylated turn motif binds in other AGC kinases forms a part of the dimerization surface. As such, transient heterodimerization of PDK1 with any of its substrates to accomplish their activation loop phosphorylation might be expected to be incompatible with docking of the turn motif to the basic patch. Intriguingly, evidence that turn motif phosphorylation results in substrate dissociation from PDK1 has previously been proposed for PRK2 (38). However, little is known about the structural details of PDK1 interaction with its substrates. One obvious hypothesis that arises from this study is that the HM of PDK1 may play an important role in substrate phosphorylation by binding to the vacant hydrophobic pocket of its substrate. Such a mechanism, in which the HMs of both the substrate and PDK1 are exchanged, would undoubtedly enhance the specificity of the interaction, with obvious consequences for signal amplification and fidelity. Further work, however, will be required to test this hypothesis.

Regardless of whether PDK1 forms a specific heterodimer with its substrate or not, our data suggests that PDK1 autoactivation and subsequent substrate phosphorylation is dependent on the presence of $\mathrm{PI}(3,4) \mathrm{P}_{2}$ or $\mathrm{PIP}_{3}$ in the membrane. Our finding that even S241 
mono-phosphorylated PDK1 adopts an autoinhibited conformation in the absence of $\mathrm{PIP}_{3}$ suggests that PDK1 may be unable to phosphorylate its substrates in the cytosol. Presumably, therefore, all PDK1 substrates must be targeted to $\mathrm{PIP}_{3}$ - or $\mathrm{PI}(3,4) \mathrm{P}_{2}$ - containing membranes in order to interact with active PDK1. Akt co-localization with PDK1 is ensured by its own $\mathrm{PH}$ domain that binds to $\mathrm{PI}(3,4) \mathrm{P}_{2}$ and $\mathrm{PIP}_{3}$. Sgk3 phosphorylation by PDK1 is likely restricted to endosomes that present both PI3P, required for Sgk3 activation, and $\mathrm{PI}(3,4) \mathrm{P}_{2}$ for PDK1 activation (43). However, the mechanism of phosphorylation of PDK1 substrates that do not contain a membrane-binding domain, such as RSK, S6K or PRK2, remains to be elucidated. Whether they require a scaffold protein that would target them to the membrane or they rely on a high-affinity interaction between their $\mathrm{HM}$ and the hydrophobic pocket of PDK1 for co-localization is not yet known. However, published data suggests that this may be the case, at least for PRK2 and S6K, which respectively encode either a constitutively high-affinity HM or a HM which exhibits a dramatic increase in affinity for PDK1 upon phosphorylation (32).

Several PDK1 substrates belong to the PI3K (Akt, SGK) or MAPK pathways (RSK), both of which are frequently dysregulated in human cancers. PDK1 is, therefore, an attractive target for therapeutic intervention. However, the development of PDK1 inhibitors is challenging, since as little as 10\% of normal PDK1 expression levels are enough to maintain viability, while the absence of PDK1 is embryonically lethal (1). So far, no PDK1 inhibitors have progressed into clinical trials. Several inhibitors targeting the hydrophobic pocket of PDK1 have been developed to target substrate-specific inhibition $(24,61)$. However, our data showing that the hydrophobic pocket of PDK1 is important for PDK1 autoactivation suggests that inhibitor binding to the pocket would impair activation of all PDK1 substrates. 
Moreover, the hydrophobic pocket is common to all AGC kinases, with obvious potential for pleiotropic, off-target effects. Our finding that PDK1 is autoinhibited by its PH domain opens up new possibilities for the development of drugs with greater specificity. Allosteric inhibitors targeting the autoinhibited conformation of Akt have been shown to be highly specific (62) with anti-tumor activity in patient-derived xenograft models of pancreatic, colon, and endometrial cancer $(63,64)$ and tumor regression and Akt signaling blockade in advanced solid tumors (65). Given the essential role of PDK1 in signal transduction downstream of growth factors and upstream of Akt, the development of allosteric inhibitors that target PDK1 may have enormous implications in the treatment of cancer.

\section{Acknowledgements}

We thank Dorothea Anrather and Markus Hartl in the Max Perutz Labs Mass Spectrometry Facility for intact mass, tandem mass spectrometry mapping of post-translational modifications, and cross-linking mass spectrometry analyses, which were performed on instruments of the Vienna BioCenter Core Facilities (VBCF). We also thank Petra Pernot for SAXS data collection on BM29 at the European Synchrotron Radiation Facility (ESRF). This work was supported by the Austrian Science Fund (FWF) in grants P30584, P33066 and W1261 to T.L. J.E.B. is supported by a Michael Smith Foundation for Health Research (MSFHR) Scholar award (17686), and an operating grant from the Cancer Research Society (CRS-24368). 


\section{Author Contributions}

A.L. purified all proteins and performed all biochemical experiments, with the exception of

HDX-MS experiments. T.L. performed in silico modeling. A.L. and T.L. analyzed SAXS data.

K.F. carried out all HDX-MS experiments and K.F. and J.B. analyzed the corresponding data.

A.L. and T.L. wrote and edited the manuscript. T.L. conceived the project.

\section{Declaration of Interests}

The authors declare no competing interests. 


\section{Materials and Methods}

\section{Protein expression and purification}

PDK1 ${ }^{\text {SKD }}$ (73-359), PDK1 LKD (73-389), N-terminal PIFtide SKD (PDK1 ${ }^{\text {PIF-SKD) }}$ or LKD (PDK1 ${ }^{\text {PIF- }}$

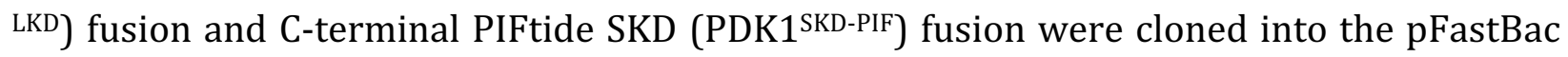

Dual expression vector with an N-terminal GST-tag for expression in baculovirus-infected Sf9 insect cells. PDK1 ${ }^{\text {SKD }}$ S241A, PDK1 ${ }^{\text {SKD }}$ Y288A, PDK1 ${ }^{\text {SKD }}$ Y288E, PDK1 ${ }^{\text {LKD }}$ F383A/M386A, PDK1 ${ }^{\text {LKD }}$ Y376A, and PDK1 ${ }^{\text {SKD-PIF }}$ S241A were generated by site-directed mutagenesis. Nearfull length PDK1 (residues 73-556; PDK1 ${ }^{\mathrm{FL}}$ ) was cloned into a pFastBac Dual expression vector with an N-terminal GST tag followed by a 3C cleavage site and a C-terminal His 10 -Strep II tag preceded by a TEV cleavage site.

All dephosphorylated proteins were purified according to the following protocol. The pellet from $0.5 \mathrm{~L}$ of baculovirus-infected Sf9 cells was lysed in $50 \mathrm{ml}$ of lysis buffer: $50 \mathrm{mM}$ Tris pH 7.5, 300 mM NaCl, 2\% glycerol, 1 mM TCEP, 0.25\% CHAPS, 1 mM PMSF, 1 mM MgCl 2 , $0.5 \mu \mathrm{l}$ benzonase $(25 \mathrm{U} / \mu \mathrm{l}), 1 \mathrm{x}$ protease inhibitor cocktail (made in-house: $100 \mu \mathrm{M}$ bestatin, $14 \mu \mathrm{M}$ E-64, $10 \mu \mathrm{M}$ pepstatin $\mathrm{A}, 1 \mu \mathrm{M}$ phosphoramidon). The lysate was cleared by centrifugation at $39000 \mathrm{~g}$ for $30 \mathrm{~min}$ and incubated with $3 \mathrm{ml}$ of glutathione sepharose beads (Cytiva) for $2 \mathrm{~h}$ at $4^{\circ} \mathrm{C}$. The beads were washed with Buffer A (50 mM Tris pH 7.5, $300 \mathrm{mM}$ NaCl, 2\% glycerol, $1 \mathrm{mM}$ TCEP) and Buffer B (50 mM Tris pH 7.5, $500 \mathrm{mM} \mathrm{NaCl,} \mathrm{2 \%} \mathrm{glycerol,}$ $1 \mathrm{mM}$ TCEP) and resuspended in Buffer A containing $1 \mathrm{mM} \mathrm{MnCl} 2$ and $40 \mu \mathrm{M}$ of lambda phosphatase (purified in-house). The protein was dephosphorylated on beads overnight at $4^{\circ} \mathrm{C}$ and the next day the beads were extensively washed with Buffer A and Buffer B to remove the lambda phosphatase. The protein was cleaved off the beads in Buffer A with 0.7 
$\mu \mathrm{M}$ of $3 \mathrm{C}$ protease (generated in-house) for $2 \mathrm{~h}$ at RT. FL constructs were cleaved with 3C and TEV to remove both tags. The cleaved protein was separated from the beads using a gravity column (Bio-Rad), salt concentration was diluted down to $250 \mathrm{mM}$ using $\mathrm{Q}_{\mathrm{A}}$ buffer (50 mM Tris $\mathrm{pH}$ 7.5, $1 \mathrm{mM}$ TCEP) and the protein was loaded on a HiTrap Q FF column (Cytiva). Protein was collected in the flow-through, concentrated, and loaded on a HiLoad S200 Increase 10/300 gel filtration column (Cytiva) equilibrated in gel filtration buffer (50 mM Tris pH 7.5, $100 \mathrm{mM} \mathrm{NaCl}$, 2\% glycerol, $1 \mathrm{mM}$ TCEP). S241A mutants were purified in the same way with the omission of the lambda phosphatase step.

The PH domain of PDK1 (408-556) was cloned into pGST parallel with an N-terminal GST-tag and transformed into BL21 STAR electrocompetent E. coli cells. Cells were grown in $4 \mathrm{~L}$ of $\mathrm{LB}$ medium containing $100 \mu \mathrm{g} / \mathrm{ml}$ ampicillin at $37^{\circ} \mathrm{C}, 200 \mathrm{rpm}$ to an $\mathrm{OD}=0.5$. They were then induced with $250 \mu \mathrm{M}$ isopropylthiogalactopyranoside (IPTG) and grown for 20h at $20^{\circ} \mathrm{C}$. Cells were centrifuged at $4000 \mathrm{~g}$ for $30 \mathrm{~min}$ and pellets were lysed in $200 \mathrm{ml}$ of lysis buffer (50 mM Tris pH 7.5, 150 mM NaCl, 10\% glucose, 1 mM EDTA, 1 mM EGTA, 1 mM TCEP, 1x protease inhibitor cocktail, $0.5 \mu \mathrm{l}$ benzonase (25 U/ $\mu \mathrm{l}$ ), $2 \mathrm{mM} \mathrm{MgCl}$, $1 \mathrm{mM} \mathrm{PMSF}, 0.25 \%$ CHAPS). The lysate was sonicated and centrifuged at $39000 \mathrm{~g}$ for $30 \mathrm{~min}$ and the supernatant was incubated with $7 \mathrm{ml}$ glutathione sepharose beads (Cytiva) for $2 \mathrm{~h}$ at $4^{\circ} \mathrm{C}$. The beads were then washed with $500 \mathrm{ml}$ of buffer A (50 mM Tris pH 7.5, $500 \mathrm{mM} \mathrm{NaCl}, 2.5 \mathrm{mM}$ DTT) and $200 \mathrm{ml}$ of Buffer B (50 mM Tris pH 7.5, $300 \mathrm{mM} \mathrm{NaCl}, 2.5 \mathrm{mM}$ DTT). The protein was cleaved off the beads with $500 \mu$ Mof 3C protease overnight. The protein was concentrated to $5 \mathrm{ml}$ and injected onto a 16/600 Superdex 200 pg column (Cytiva) equilibrated in buffer B. 


\section{Intact mass spectrometry}

Intact protein samples were diluted in $\mathrm{H}_{2} \mathrm{O}$ and up to 100 ng protein were loaded on an XBridge Protein BEH C4 column (2.5 $\mu$ m particle size, dimensions $2.1 \mathrm{~mm} \mathrm{X} 150 \mathrm{~mm}$; Waters) using a Dionex Ultimate 3000 HPLC system (Thermo Fisher Scientific) with a working temperature of $50{ }^{\circ} \mathrm{C}, 0.1 \%$ formic acid (FA) as solvent $\mathrm{A}, 80 \%$ acetonitrile, $0.08 \% \mathrm{FA}$ as solvent B. Proteins were separated with a 6 min step gradient from 10 to $80 \%$ solvent B at a flow rate of $300 \mu \mathrm{L} / \mathrm{min}$ and analysed on a Synapt G2-Si coupled via a ZSpray ESI source (Waters). Data were recorded with MassLynx V 4.1 (Waters) and analyzed using the MaxEnt 1 process to reconstruct the uncharged average protein mass.

\section{Mass spectrometry of cross-linked samples}

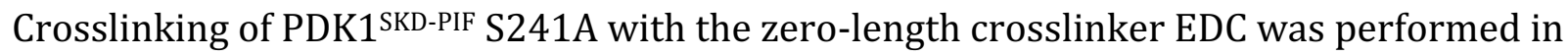
$40 \mathrm{mM}$ MES pH 6.5, $100 \mathrm{mM} \mathrm{NaCl} 10 \mu \mathrm{M}$ protein was mixed with $2 \mathrm{mM}$ EDC, 5 mM SulfoNHS, $1 \mathrm{mM}$ ATP and $2 \mathrm{mM} \mathrm{MgCl} 2$ and incubated for $1 \mathrm{~h}$ at RT in the dark. The reaction was quenched with $50 \mathrm{mM}$ Tris pH 7.5 and $20 \mathrm{mM}$ beta-mercaptoethanol, $15 \mathrm{~min}$ at RT. Crosslinked monomer and dimer species were separated by polyacrylamide gel electrophoresis. Gel bands were excised, cut up, and destained with acetonitrile (ACN) and $50 \mathrm{mM}$ ammonium bicarbonate $(\mathrm{ABC})$. Before each of the following reaction steps, gel pieces were washed with $50 \mathrm{mM} \mathrm{ABC}$ and dehydrated in $100 \%$ ACN in order to facilitate the uptake of the solutions. Disulfide bridges were reduced in $10 \mathrm{mM}$ dithiothreitol in $50 \mathrm{mM}$ ABC for 30 $\min$ at $56^{\circ} \mathrm{C}$. Subsequently the free thiols were alkylated with $50 \mathrm{mM}$ iodoacetamide in 50 mM ABC in the dark (30 min at RT). Proteins were digested with trypsin (Promega) in 50 $\mathrm{mM} A B C$ overnight at $37^{\circ} \mathrm{C}$. The reaction was stopped by adding $10 \mu \mathrm{l}$ of $10 \%(\mathrm{v} / \mathrm{v})$ formic 
acid (FA) and petides were extracted by sonication with 5\% FA, 50\% ACN. The samples were dried in the vacuum centrifuge and taken up in $0.1 \%$ trifluoro acetic acid, $2 \%$ ACN. Peptide samples were injected on an Ultimate 3000 RSLC nano-flow chromatography system, set up with a pre-column for sample loading (PepMapAcclaim C18, $2 \mathrm{~cm} \times 0.1 \mathrm{~mm}$, $5 \mu \mathrm{m}$ ). Peptides were separated on the C18 analytical column (PepMapAcclaim C18, $50 \mathrm{~cm}$ $\times 0.75 \mathrm{~mm}, 2 \mu \mathrm{m}$; all HPLC parts Thermo Fisher Scientific) applying a linear gradient from 2 to $40 \%$ of solvent $\mathrm{B}(80 \% \mathrm{ACN}, 0.08 \% \mathrm{FA}$; solvent $\mathrm{A} 0.1 \% \mathrm{FA})$ at a flow rate of $230 \mathrm{nl} / \mathrm{min}$ over 120 minutes. Eluting peptides were analyzed on an Orbitrap Fusion Lumos mass spectrometer (Thermo Fisher Scientific). For the data-dependent mode, survey scans were acquired in the $\mathrm{m} / \mathrm{z}$ range of 350-1550 at a resolution of 120.000 at $200 \mathrm{~m} / \mathrm{z}$, with lock mass on. The AGC target value was set to 4E5 with a maximal injection time of $50 \mathrm{~ms}$. The 15 most intense ions were selected within an isolation width of 1.2 Thomson, fragmented in the HCD cell with a normalized collision energy of $30 \%$. Spectra were recorded at a target value of $1 \mathrm{E} 5$ with a maximal injection time of $200 \mathrm{~ms}$ and a resolution of 30000 . Only peptides with an assigned charge state between +3 and +6 were selected for fragmentation, the peptide match and exclude isotope features were enabled and selected precursors were dynamically excluded from repeated sampling for 30 s. The MaxQuant software package, version 1.6.0.16 (66) was used to identify the most abundant protein hits searching against the sequence of the PDK1 chimera protein, the proteome of Bombyx mori and Spodoptera from uniprot (2019.01 UP000005204_7091_Bombyx_mori_all.fasta, 2019.09_Spodoptera.fasta) and common contaminants. Search settings were set to default values. To identify cross-linked peptides, the spectra were searched against the sequences of the top 10 proteins from the MQ search sorted by iBAQ using pLink software v2.3.9 (67). 
Carbamidomethylation of cysteine was set as fixed, and oxidation of methionine as variable modification. The enzyme specificity was set to tryptic allowing 4 missed cleavage sites, and EDC/sulfo-NHS was specified according to the cross-linking chemistry. Search results were filtered for 1\% FDR (false discovery rate) on the PSM level (peptide-spectrum matches) and a maximum precursor mass deviation of $5 \mathrm{ppm}$. To remove low quality PSMs, additionally an e-Value cutoff of $<0.001$ was applied. The mass spectrometry proteomics data have been deposited to the ProteomeXchange Consortium via the PRIDE (68) partner repository with the dataset identifier PXD026933.

\section{In silico modeling}

The structure of monomeric PDK1 S241A (PDB: 2biy) was modified to remove activation loop residues 223-245, the conformation of which is unknown for a putative dimeric assembly undergoing trans-autophosphorylation. The remainder of the model was not modified. Two independent approaches to modeling a homodimer were employed. In the first, the ROSETTA Symmetric Docking protocol (21) was used to model the dimer by imposing C2 symmetry and searching for dyad-symmetric assemblies with the lowest free energy of docking. The best hit from the modeling was further refined using the ROSETTA protocol for local refinement. The final model was then used to search the Protein Data Bank for homologous assemblies and to design interface mutations to test the model. In the second approach, AlphaFold2 $(22,23)$ was used to predict the homodimer for residues Q73-T359. Modeling was performed with and without experimental structure input (templates) and the 
output models compared to ROSETTA by calculating the r.m.s.d. over all $\mathrm{C}_{\alpha}$ atoms for both chains.

Size exclusion chromatography coupled to multi-angle light scattering (SEC-MALS)

The oligomeric state and polydispersity of purified recombinant proteins were assessed by SEC-MALS. $50 \mu \mathrm{l}$ of PDK1 ${ }^{\text {SKD }}$ S241A (3 mg/ml), PDK1LKD S241A (5 mg/ml), PDK1FL S241A

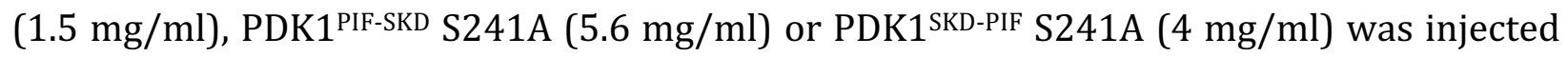
onto a Superdex 200 10/300 column (Cytiva) operated by a 1260 Infinity HPLC (Agilent Technologies). Light scattering of a $690 \mathrm{~nm}$ laser was detected by a MiniDawn Treos (Wyatt) and the refractive index was measured by a Shodex RI-101 (Shodex) detector. The runs were done in $50 \mathrm{mM}$ Tris pH 7.5, $100 \mathrm{mM} \mathrm{NaCl}, 2 \%$ glycerol, $1 \mathrm{mM}$ TCEP, $2 \mathrm{mM} \mathrm{MgCl}$, + /- $1 \mathrm{mM}$ ATP.

\section{Radiometric kinase assay}

Autophosphorylation reactions were done using radiolabeled $\left[\gamma^{32} \mathrm{P}\right]$ ATP (Hartman Analytic). All reactions were performed in the following buffer: $25 \mathrm{mM}$ Tris pH 7.5, $100 \mathrm{mM}$ $\mathrm{NaCl}, 2 \%$ glycerol, $5 \mathrm{mM}$ DTT. In the reactions comparing autophosphorylation kinetics between PDK1 $1^{\text {SKD }}$, PDK1 $1^{\text {SKD }}$ Y288A and PDK1 ${ }^{\text {SKD }}$ Y288E; PDK1 ${ }^{\text {SKD }}$ and PDK1 $1^{\text {PIF-SKD; PDK1 }}$ SKD and PDK1 ${ }^{\mathrm{LKD}}, 5 \mu \mathrm{M}$ of dephosphorylated protein, $200 \mu \mathrm{M}$ of ATP (Promega) spiked 1:10 with $\left[\gamma^{-32} \mathrm{P}\right]$ ATP and $400 \mu \mathrm{M} \mathrm{MgCl} 2$ were added to the buffer. In the reactions comparing autophosphorylation kinetics between PDK1 ${ }^{\text {LKD }}$, PDK1 $1^{\text {PIF-LKD }}$ and PDK1 $1^{\text {PIF-SKD; PDK1 }}$ LKD, PDK1 $^{\mathrm{FL}}$ and PDK1 ${ }^{\text {SKD }}$; PDK1 ${ }^{\mathrm{LKD}}$ and PDK1 ${ }^{\mathrm{LKD}}$ F383A/M386A; PDK1LKD and PDK1LKD Y376A, 1 $\mu \mathrm{M}$ of dephosphorylated protein, $50 \mu \mathrm{M}$ ATP $\left(1: 10\left[\gamma^{-32} \mathrm{P}\right] \mathrm{ATP}\right)$ and $100 \mu \mathrm{M} \mathrm{MgCl}_{2}$ were 
added to the buffer. At every time point $(5,10,15,30,45 \mathrm{~min}, 1$ and 2 hour), $20 \mu$ l aliquots were taken from the reaction and mixed with $5 \mu$ l of 500 mM EDTA to terminate the reaction. The quenched reactions were spotted on $0.45 \mu \mathrm{m}$ nitrocellulose membrane (Cytiva). The membrane was washed $4 \times 5$ min with $50 \mathrm{ml}$ of $75 \mathrm{mM} \mathrm{H}_{3} \mathrm{PO}_{4}$ to remove non-incorporated ATP. The washed membranes were placed in scintillation tubes containing $5 \mathrm{ml}$ of $\mathrm{dH}_{2} \mathrm{O}$. Cerenkov radiation was measured with a Tri-Carb 4910 TR liquid scintillator (Perkin Elmer). Phosphate incorporation in the assay comparing PDK1 ${ }^{\mathrm{LKD}}$ to PDK1 LKD Y376A was quantified by phosphorimaging. The washed membrane was wrapped in Saran film and exposed to a phosphor screen in a cassette overnight. The screen was imaged with an Amersham Typhoon phosphorimager and the radioactive signal was quantified in ImageJ.

\section{Hydrogen-Deuterium Exchange Mass Spectrometry}

\section{Sample preparation}

HDX reactions for PDK1 ${ }^{\text {SKD }}$ S241A (monomer) and PDK1 ${ }^{\text {SKD-PIF }}$ S241A (dimer) were conducted in a final reaction volume of $10 \mu \mathrm{L}$ with a final concentration of $6.7 \mu \mathrm{M}$ and 26.8 $\mu \mathrm{M}$ for PDK1 ${ }^{\text {SKD }}$ S241A and PDK1 ${ }^{\text {SKD-PIF }}$ S241A, respectively. The reaction was initiated by the addition of $7.0 \mu \mathrm{L}$ of D20 buffer (20mM pH7.5 HEPES, 100mM NaCl, 94\% D20 (V/V)) to 3.0 $\mu \mathrm{L}$ of protein solution (final D20 concentration of $66 \%$ ). The reaction proceeded for 3,30 , 300 , or 3000 s at $18^{\circ} \mathrm{C}$, before being quenched with ice cold acidic quench buffer, resulting in a final concentration of $0.6 \mathrm{M}$ guanidine- $\mathrm{HCl}$ and $0.9 \%$ formic acid post quench. All conditions were stored at $-80^{\circ} \mathrm{C}$, and timepoints were created and run in triplicate. 
HDX reactions comparing PDK1 $1^{\mathrm{FL}}$ and $\mathrm{PDK} 1^{\mathrm{SKD}}$ were conducted in a final reaction volume of $20 \mu \mathrm{L}$ with a final protein concentration of $26 \mu \mathrm{M}$. The reaction was initiated by the addition of $45 \mu \mathrm{L}$ of D20 buffer (20mM pH7.5 HEPES, $100 \mathrm{mM} \mathrm{NaCl}, 94 \%$ D2O (V/V)) to $5.0 \mu \mathrm{L}$ of protein solution (final D20 concentration of $89.6 \%$ ). The reaction proceeded for $3 \mathrm{~s}$ at $4^{\circ} \mathrm{C}$ and $3,30,300$, or 3000 s at $18^{\circ} \mathrm{C}$, before being quenched with ice cold acidic quench buffer, resulting in a final concentration of $0.6 \mathrm{M}$ guanidine- $\mathrm{HCl}$ and $0.9 \%$ formic acid post quench. All conditions were stored at $-80^{\circ} \mathrm{C}$, and timepoints were created and run in triplicate.

HDX reactions comparing $\mathrm{PDK} 1^{\mathrm{FL}}$ and $\mathrm{PDK} 1^{\mathrm{PH}}$ were conducted in a final reaction volume of $50 \mu \mathrm{L}$ with a final protein concentration of $5 \mu \mathrm{M}$. The reaction was initiated by the addition of $19 \mu \mathrm{L}$ of D20 buffer (50mM pH7.5 HEPES, 100mM NaCl, 94\% D20 (V/V)) to 1.0 $\mu \mathrm{L}$ of protein solution (final D20 concentration of $81.2 \%$ ). The reaction proceeded for 3s at $4^{\circ} \mathrm{C}$ and $3,30,300$, or 3000 s at $18^{\circ} \mathrm{C}$, before being quenched with ice cold acidic quench buffer, resulting in a final concentration of $0.6 \mathrm{M}$ guanidine- $\mathrm{HCl}$ and $0.9 \%$ formic acid post quench. All conditions and timepoints were created and run in triplicate. Samples were flash frozen immediately after quenching and stored at $-80^{\circ} \mathrm{C}$ until injected onto the ultraperformance liquid chromatography (UPLC) system for proteolytic cleavage, peptide separation, and injection onto a QTOF for mass analysis, described below.

\section{Protein digestion and MS/MS data collection}

Protein samples were rapidly thawed and injected onto an integrated fluidics system containing a HDx-3 PAL liquid handling robot and climate-controlled $\left(2^{\circ} \mathrm{C}\right)$ chromatography system (LEAP Technologies), a Dionex Ultimate 3000 UHPLC system, as well as an Impact 
HD QTOF Mass spectrometer (Bruker). The protein was run over either one (at $10^{\circ} \mathrm{C}$ ) or two (at $10^{\circ} \mathrm{C}$ and $2^{\circ} \mathrm{C}$ ) immobilized pepsin columns (Trajan; ProDx protease column, $2.1 \mathrm{~mm} \times 30$ mm PDX.PP01-F32) at $200 \mu \mathrm{L} / \mathrm{min}$ for 3 minutes. The resulting peptides were collected and desalted on a C18 trap column (Acquity UPLC BEH C18 1.7mm column (2.1 x 5 mm); Waters 186003975). The trap was subsequently eluted in line with an ACQUITY $1.7 \mu$ m particle, 100 $\times 1 \mathrm{~mm} 2$ C18 UPLC column (Waters), using a gradient of 3-35\% B (Buffer A 0.1\% formic acid; Buffer B 100\% acetonitrile) over 11 minutes immediately followed by a gradient of 35-80\% over 5 minutes. Full details of all LC methods can be found at (69). Mass spectrometry experiments acquired over a mass range from 150 to $2200 \mathrm{~m} / \mathrm{z}$ using an electrospray ionization source operated at a temperature of $200 \mathrm{C}$ and a spray voltage of $4.5 \mathrm{kV}$.

\section{Peptide identification}

Peptides were identified from the non-deuterated samples of PDK1 using data-dependent acquisition following tandem MS/MS experiments (0.5 s precursor scan from 150-2000 m/z; twelve $0.25 \mathrm{~s}$ fragment scans from 150-2000 m/z). MS/MS datasets were analysed using PEAKS7 (PEAKS), and peptide identification was carried out by using a false discovery based approach, with a threshold set to $1 \%$ using a database of known contaminants found in Sf9 and E. coli cells (70). The search parameters were set with a precursor tolerance of $20 \mathrm{ppm}$, fragment mass error $0.02 \mathrm{Da}$, charge states from 1-8, leading to a selection criterion of peptides that had $-10 \log P$ scores of $31.8,30.7,19.7$, and 19.1 .

\section{Mass analysis of peptide centroids and measurement of deuterium incorporation}

HD-Examiner Software (Sierra Analytics) was used to automatically calculate the level of deuterium incorporation into each peptide. All peptides were manually inspected for correct 
charge state, correct retention time, appropriate selection of isotopic distribution, etc.

Deuteration levels were calculated using the centroid of the experimental isotope clusters.

Results are presented as relative levels of deuterium incorporation, no correction for back exchange, and with the only correction being applied correcting for the deuterium oxide percentage of the buffer utilized in the exchange $(66 \%, 75.5 \%, 89.6 \%$, and $81.2 \%$ ) Differences in exchange in a peptide were considered significant if they met all three of the following criteria: : $\geq 5 \%$ change in exchange, $\geq 0.4$ Da difference in exchange, and a two tailed t-test value of $\mathrm{p}<0.01$. The raw HDX data are shown in two different formats. Samples were only compared within a single experiment and were never compared to experiments completed at a different time with a different final D20 level. The data analysis statistics for all HDX-MS experiments are in Supplementary Table 4 according to the guidelines of (71). The mass spectrometry proteomics data have been deposited to the ProteomeXchange Consortium via the PRIDE partner repository (68) with the dataset identifier PXD027401.

\section{Small-angle X-ray scattering (SAXS)}

SAXS data for unphosphorylated and S241-monophosphorylated PDK1 ${ }^{\mathrm{FL}}$ were collected on BM29 at the ESRF, Grenoble, France using an in-line SEC-SAXS setup. Proteins were applied to a Agilent Bio SEC 300 column equilibrated in 20 mM Tris, pH 7.4, $150 \mathrm{mM} \mathrm{NaCl,} 1 \mathrm{mM}$ DTT, 1 mM EDTA and $1 \%(v / v)$ glycerol and images were acquired every second for the duration of the size exclusion run. Buffer subtraction was performed by averaging 50 frames either side of the peak. All subsequent data processing steps were performed using 
the ATSAS data analysis software 3.9.1. The program DATGNOM (72) was used to generate the pair distribution function $[\mathrm{P}(\mathrm{r})]$ for each isoform and to determine $\mathrm{D}_{\max }$ and $\mathrm{R}_{\mathrm{g}}$ from the scattering curves $[\mathrm{I}(\mathrm{q})$ vs. q] in an automatic, unbiased manner.

\section{Preparation of sucrose loaded vesicles (SLVs) and pelleting assay}

Cholesterol, DOPC, DOPS and DOPE were dissolved in chloroform, and $\mathrm{PIP}_{3}$ was dissolved in a chloroform:methanol:water (1:2:0.8) mixture. To generate SLVs, lipids were mixed in the following molar ratio: 20\% cholesterol, 30\% DOPC, 15\% DOPS, 35\% DOPE and 0-2\% PIP 3 was added at the expense of DOPC. The lipid mixture was first dried under a nitrogen stream and then rehydrated in $20 \mathrm{mM}$ HEPES pH 7.4, 0.3M sucrose buffer. Lipid mixtures were then frozen in liquid nitrogen and sonicated at RT. The freeze-thawing steps were repeated four times after which the vesicles were pelleted in a Beckman Coulter Optima MAX-XP Ultracentrifuge using a TLA 100 rotor operated at $50000 \mathrm{rpm} / 20^{\circ} \mathrm{C}$ for $30 \mathrm{~min}$. Liposome pellets were then resuspended in the reaction buffer $(50 \mathrm{mM}$ Tris $\mathrm{pH} 7.5,150 \mathrm{mM} \mathrm{NaCl}, 1$ $\mathrm{mM}$ TCEP) to a final lipid concentration of $1 \mathrm{mM} .2 \mu \mathrm{M}$ of PDK1 ${ }^{\mathrm{FL}}$ and $2 \mu \mathrm{M}$ PDK1 ${ }^{\mathrm{PH}}$ were mixed 1:1 with liposomes in $50 \mu$ final volume and the mixture was incubated for $30 \mathrm{~min}$. After that, the reaction was spun down at $9800 \mathrm{~g}$ for $30 \mathrm{~min}$ at $20^{\circ} \mathrm{C}$. The supernatant was collected and the pellet was resuspended in the reaction buffer. Equal volumes of supernatant and pellet were loaded on the SDS-PAGE and the fraction of protein bound to the liposomes was determined by Coomassie densitometry. 


\section{References}

1. Lawlor MA, Mora A, Ashby PR, Williams MR, Murray-Tait V, Malone L, Prescott AR, Lucocq JM, Alessi DR (2002) Essential role of PDK1 in regulating cell size and development in mice. EMBO J 21(14):3728-38.

2. Zhao JJ, et al. (2009) 3-Phosphoinositide-Dependent Kinase 1 Potentiates Upstream Lesions on the Phosphatidylinositol 3-Kinase Pathway in Breast Carcinoma. Cancer Res 69(15):6299-6306.

3. Ahmed N, Riley C, Quinn MA (2008) An immunohistochemical perspective of PPAR $\beta$ and one of its putative targets PDK1 in normal ovaries, benign and malignant ovarian tumours. Br J Cancer 98(8):1415-1424.

4. Pietri M, Dakowski C, Hannaoui S, Alleaume-Butaux A, Hernandez-Rapp J, Ragagnin A, Mouillet-Richard S, Haik S, Bailly Y, Peyrin J-M, Launay J-M, Kellermann O, Schneider B (2013) PDK1 decreases TACE-mediated $\alpha$-secretase activity and promotes disease progression in prion and Alzheimer's diseases. Nat Med 19(9):1124-1131.

5. Pearce LR, Komander D, Alessi DR (2010) The nuts and bolts of AGC protein kinases. Nat Rev Mol Cell Biol 11(1):9-22.

6. Fruman DA, Chiu H, Hopkins BD, Bagrodia S, Cantley LC, Abraham RT (2017) The PI3K Pathway in Human Disease. Cell 170(4):605-635.

7. Manning BD, Toker A (2017) AKT/PKB Signaling: Navigating the Network. Cell 
$169(3): 381-405$.

8. Currie RA, Walker KS, Gray A, Deak M, Casamayor A, Downes CP, Cohen P, Alessi DR, Lucocq J (1999) Role of phosphatidylinositol 3,4,5-trisphosphate in regulating the activity and localization of 3-phosphoinositide-dependent protein kinase-1. Biochem J 337 ( Pt 3(3):575-83.

9. Casamayor A, Morrice NA, Alessi DR (1999) Phosphorylation of Ser-241 is essential for the activity of 3-phosphoinositide-dependent protein kinase-1: identification of five sites of phosphorylation in vivo. Biochem J 342 ( Pt 2(2):287-92.

10. Frödin M, Jensen CJ, Merienne K, Gammeltoft S (2000) A phosphoserine-regulated docking site in the protein kinase RSK2 that recruits and activates PDK1. EMBO J 19(12):2924-34.

11. Masters TA, Calleja V, Armoogum DA, Marsh RJ, Applebee CJ, Laguerre M, Bain AJ, Larijani B (2010) Regulation of 3-phosphoinositide-dependent protein kinase 1 activity by homodimerization in live cells. Sci Signal 3(145):ra78.

12. Gao X, Lowry PR, Zhou X, Depry C, Wei Z, Wong GW, Zhang J (2011) PI3K/Akt signaling requires spatial compartmentalization in plasma membrane microdomains. Proc Natl Acad Sci U S A 108(35):14509-14.

13. Ziemba BP, Pilling C, Calleja V, Larijani B, Falke JJ (2013) The PH domain of phosphoinositide-dependent kinase-1 exhibits a novel, phospho-regulated monomer-dimer equilibrium with important implications for kinase domain 
activation: single-molecule and ensemble studies. Biochemistry 52(28):4820-9.

14. Anderson KE, Coadwell J, Stephens LR, Hawkins PT (1998) Translocation of PDK-1 to the plasma membrane is important in allowing PDK-1 to activate protein kinase B. Curr Biol 8(12):684-91.

15. Filippa N, Sable CL, Hemmings BA, Van Obberghen E (2000) Effect of phosphoinositide-dependent kinase 1 on protein kinase B translocation and its subsequent activation. Mol Cell Biol 20(15):5712-21.

16. Tamgüney T, Zhang C, Fiedler D, Shokat K, Stokoe D (2008) Analysis of 3phosphoinositide-dependent kinase-1 signaling and function in ES cells. Exp Cell Res 314(11-12):2299-312.

17. Lim MA, Kikani CK, Wick MJ, Dong LQ (2003) Nuclear translocation of 3'phosphoinositide-dependent protein kinase 1 (PDK-1): a potential regulatory mechanism for PDK-1 function. Proc Natl Acad Sci U S A 100(24):14006-11.

18. Wick MJ, Ramos FJ, Chen H, Quon MJ, Dong LQ, Liu F (2003) Mouse 3phosphoinositide-dependent protein kinase-1 undergoes dimerization and transphosphorylation in the activation loop.J Biol Chem 278(44):42913-9.

19. Riojas RA, Kikani CK, Wang C, Mao X, Zhou L, Langlais PR, Hu D, Roberts JL, Dong LQ, Liu F (2006) Fine tuning PDK1 activity by phosphorylation at Ser163. J Biol Chem 281(31):21588-21593.

20. Hein MY, Hubner NC, Poser I, Cox J, Nagaraj N, Toyoda Y, Gak IA, Weisswange I, 
Mansfeld J, Buchholz F, Hyman AA, Mann M (2015) A human interactome in three quantitative dimensions organized by stoichiometries and abundances. Cell 163(3):712-23.

21. DiMaio F, Leaver-Fay A, Bradley P, Baker D, André I (2011) Modeling Symmetric Macromolecular Structures in Rosetta3. PLoS One 6(6):e20450.

22. Mirdita M, Ovchinnikov S, Steinegger M (2021) ColabFold - Making protein folding accessible to all. bioRxiv:2021.08.15.456425.

23. Jumper J, et al. (2021) Highly accurate protein structure prediction with AlphaFold. Nature:1-7.

24. Hindie V, Stroba A, Zhang H, Lopez-Garcia LA, Idrissova L, Zeuzem S, Hirschberg D, Schaeffer F, Jørgensen TJD, Engel M, Alzari PM, Biondi RM (2009) Structure and allosteric effects of low-molecular-weight activators on the protein kinase PDK1. Nat Chem Biol 5(10):758-64.

25. Kannan N, Haste N, Taylor SS, Neuwald AF (2007) The hallmark of AGC kinase functional divergence is its C-terminal tail, a cis-acting regulatory module. Proc Natl Acad Sci U S A 104(4):1272-7.

26. Bornancin F, Parker PJ (1997) Phosphorylation of Protein Kinase C- $\alpha$ on Serine 657 Controls the Accumulation of Active Enzyme and Contributes to Its Phosphataseresistant State. J Biol Chem 272(6):3544-3549.

27. Edwards AS, Newton AC (1997) Phosphorylation at conserved carboxyl-terminal 
hydrophobic motif regulates the catalytic and regulatory domains of protein kinase C. J Biol Chem 272(29):18382-90.

28. Couzens AL, Saridakis V, Scheid MP (2009) The hydrophobic motif of ROCK2 requires association with the $\mathrm{N}$-terminal extension for kinase activity. Biochem J 419(1):141-8.

29. Yang J, Cron P, Thompson V, Good VM, Hess D, Hemmings BA, Barford D (2002) Molecular Mechanism for the Regulation of Protein Kinase B/Akt by Hydrophobic Motif Phosphorylation. Mol Cell 9(6):1227-1240.

30. Biondi RM, Cheung PCF, Casamayor A, Deak M, Currie RA, Alessi DR (2000) Identification of a pocket in the PDK1 kinase domain that interacts with PIF and the C-terminal residues of PKA. EMBO J 19(5):979-88.

31. Balendran A, Biondi RM, Cheung PC, Casamayor A, Deak M, Alessi DR (2000) A 3phosphoinositide-dependent protein kinase-1 (PDK1) docking site is required for the phosphorylation of protein kinase Czeta (PKCzeta ) and PKC-related kinase 2 by PDK1.J Biol Chem 275(27):20806-13.

32. Biondi RM, Kieloch A, Currie RA, Deak M, Alessi DR (2001) The PIF-binding pocket in PDK1 is essential for activation of S6K and SGK, but not PKB. EMBO J 20(16):438090.

33. Frödin M, Antal TL, Dümmler BA, Jensen CJ, Deak M, Gammeltoft S, Biondi RM (2002) A phosphoserine/threonine-binding pocket in AGC kinases and PDK1 mediates 
activation by hydrophobic motif phosphorylation. EMBO J 21(20):5396-407.

34. Biondi RM, Komander D, Thomas CC, Lizcano JM, Deak M, Alessi DR, van Aalten DMF (2002) High resolution crystal structure of the human PDK1 catalytic domain defines the regulatory phosphopeptide docking site. EMBO J 21(16):4219-28.

35. Najafov A, Shpiro N, Alessi DR (2012) Akt is efficiently activated by PIF-pocket- and PtdIns(3,4,5)P3-dependent mechanisms leading to resistance to PDK1 inhibitors. Biochem J 448(2):285-95.

36. Schulze JO, Saladino G, Busschots K, Neimanis S, Süß E, Odadzic D, Zeuzem S, Hindie V, Herbrand AK, Lisa M-N, Alzari PM, Gervasio FL, Biondi RM (2016) Bidirectional Allosteric Communication between the ATP-Binding Site and the Regulatory PIF Pocket in PDK1 Protein Kinase. Cell Chem Biol 23(10):1193-1205.

37. Busschots K, Lopez-Garcia LA, Lammi C, Stroba A, Zeuzem S, Piiper A, Alzari PM, Neimanis S, Arencibia JM, Engel M, Schulze JO, Biondi RM (2012) Substrate-selective inhibition of protein kinase PDK1 by small compounds that bind to the PIF-pocket allosteric docking site. Chem Biol 19(9):1152-1163.

38. Dettori R, Sonzogni S, Meyer L, Lopez-Garcia LA, Morrice NA, Zeuzem S, Engel M, Piiper A, Neimanis S, Frödin M, Biondi RM (2009) Regulation of the Interaction between Protein Kinase C-related Protein Kinase 2 (PRK2) and Its Upstream Kinase, 3-Phosphoinositide-dependent Protein Kinase 1 (PDK1). J Biol Chem 284(44):3031830327. 
39. Takimura T, Kamata K, Fukasawa K, Ohsawa H, Komatani H, Yoshizumi T, Takahashi I, Kotani H, Iwasawa Y (2010) Structures of the PKC-l kinase domain in its ATP -

Bound and apo forms reveal defined structures of residues 533-551 in the C-terminal tail and their roles in ATP binding. Acta Crystallogr Sect D Biol Crystallogr 66(5):577583.

40. Batkin M, Schvartz I, Shaltiel S (2000) Snapping of the carboxyl terminal tail of the catalytic subunit of PKA onto its core: characterization of the sites by mutagenesis. Biochemistry 39(18):5366-73.

41. Ebner M, Lučić I, Leonard TA, Yudushkin I (2017) PI(3,4,5)P3Engagement Restricts Akt Activity to Cellular Membranes. Mol Cell 65(3):416-431.e6.

42. Lučić I, Rathinaswamy MK, Truebestein L, Hamelin DJ, Burke JE, Leonard TA (2018) Conformational sampling of membranes by Akt controls its activation and inactivation. Proc Natl Acad Sci U S A 115(17):E3940-E3949.

43. Pokorny D, Truebestein L, Fleming KD, Burke JE, Leonard TA (2021) In vitro reconstitution of Sgk3 activation by phosphatidylinositol 3-phosphate. J Biol Chem 297(2):100919.

44. Ebner M, Lučić I, Leonard TA, Yudushkin I (2017) PI(3,4,5)P3 Engagement Restricts Akt Activity to Cellular Membranes. Mol Cell 65(3):416-431.e6.

45. Oancea E, Meyer T (1998) Protein kinase C as a molecular machine for decoding calcium and diacylglycerol signals. Cell 95(3):307-18. 
46. Leonard TA, Róycki B, Saidi LF, Hummer G, Hurley JH (2011) Crystal structure and allosteric activation of protein kinase C $\beta$ iI. Cell 144(1):55-66.

47. Elsner DJ, Siess KM, Gossenreiter T, Hartl M, Leonard TA (2019) A ubiquitin-like domain controls protein kinase D dimerization and activation by transautophosphorylation. J Biol Chem 294(39):14422-14441.

48. Haling JR, Sudhamsu J, Yen I, Sideris S, Sandoval W, Phung W, Bravo BJ, Giannetti AM, Peck A, Masselot A, Morales T, Smith D, Brandhuber BJ, Hymowitz SG, Malek S (2014) Structure of the BRAF-MEK complex reveals a kinase activity independent role for BRAF in MAPK signaling. Cancer Cell 26(3):402-413.

49. Park E, Rawson S, Li K, Kim B-W, Ficarro SB, Pino GG-D, Sharif H, Marto JA, Jeon H, Eck MJ (2019) Architecture of autoinhibited and active BRAF-MEK1-14-3-3 complexes. Nature:1-5.

50. Kim C, Cheng CY, Saldanha SA, Taylor SS (2007) PKA-I Holoenzyme Structure Reveals a Mechanism for cAMP-Dependent Activation. Cell 130(6):1032-1043.

51. Patel AK, Yadav RP, Majava V, Kursula I, Kursula P, Patel AK (2011) Structure of the Dimeric Autoinhibited Conformation of DAPK2, a Pro-Apoptotic Protein Kinase. J Mol Biol 409:369-383.

52. Dar AC, Dever TE, Sicheri F (2005) Higher-order substrate recognition of eIF2alpha by the RNA-dependent protein kinase PKR. Cell 122(6):887-900.

53. Song H, Hanlon N, Brown NR, Noble MEM, Johnson LN, Barford D (2001) 
Phosphoprotein-Protein Interactions Revealed by the Crystal Structure of KinaseAssociated Phosphatase in Complex with PhosphoCDK2. Mol Cell 7(3):615-626.

54. Wick MJ, Wick KR, Chen H, He H, Dong LQ, Quon MJ, Liu F (2002) Substitution of the autophosphorylation site Thr516 with a negatively charged residue confers constitutive activity to mouse 3-phosphoinositide-dependent protein kinase-1 in cells. J Biol Chem 277(19):16632-8.

55. McManus EJ, Collins BJ, Ashby PR, Prescott AR, Murray-Tait V, Armit LJ, Arthur JSC, Alessi DR (2004) The in vivo role of PtdIns(3,4,5)P3binding to PDK1 PH domain defined by knockin mutation. EMBO J 23(10):2071-2082.

56. Bayascas JR, Wullschleger S, Sakamoto K, García-Martínez JM, Clacher C, Komander D, van Aalten DMF, Boini KM, Lang F, Lipina C, Logie L, Sutherland C, Chudek JA, van Diepen JA, Voshol PJ, Lucocq JM, Alessi DR (2008) Mutation of the PDK1 PH domain inhibits protein kinase B/Akt, leading to small size and insulin resistance. Mol Cell Biol 28(10):3258-72.

57. Scheid MP, Parsons M, Woodgett JR (2005) Phosphoinositide-dependent phosphorylation of PDK1 regulates nuclear translocation. Mol Cell Biol 25(6):234763.

58. Ananthanarayanan B, Ni Q, Zhang J (2005) Signal propagation from membrane messengers to nuclear effectors revealed by reporters of phosphoinositide dynamics and Akt activity. Proc Natl Acad Sci U S A 102(42):15081-6. 
59. Oh WJ, Wu C, Kim SJ, Facchinetti V, Julien L-A, Finlan M, Roux PP, Su B, Jacinto E (2010) mTORC2 can associate with ribosomes to promote cotranslational phosphorylation and stability of nascent Akt polypeptide. EMBO J 29(23):39393951.

60. Facchinetti V, Ouyang W, Wei H, Soto N, Lazorchak A, Gould C, Lowry C, Newton AC, Mao Y, Miao RQ, Sessa WC, Qin J, Zhang P, Su B, Jacinto E (2008) The mammalian target of rapamycin complex 2 controls folding and stability of Akt and protein kinase C. EMBO J 27(14):1932-43.

61. Rettenmaier TJ, Sadowsky JD, Thomsen ND, Chen SC, Doak AK, Arkin MR, Wells JA (2014) A small-molecule mimic of a peptide docking motif inhibits the protein kinase PDK1. Proc Natl Acad Sci U S A 111(52):18590-5.

62. Wu W-I, Voegtli WC, Sturgis HL, Dizon FP, Vigers GPA, Brandhuber BJ (2010) Crystal structure of human AKT1 with an allosteric inhibitor reveals a new mode of kinase inhibition. PLoS One 5(9):e12913.

63. Weisner J, et al. (2019) Preclinical Efficacy of Covalent-Allosteric AKT Inhibitor Borussertib in Combination with Trametinib in KRAS-mutant Pancreatic and Colorectal Cancer. Cancer Res 79(9):canres.2861.2018.

64. Lapierre J-M, et al. (2016) Discovery of 3-(3-(4-(1-Aminocyclobutyl)phenyl)-5phenyl-3H-imidazo[4,5-b]pyridin-2-yl)pyridin-2-amine (ARQ 092): An Orally Bioavailable, Selective, and Potent Allosteric AKT Inhibitor. J Med Chem 59(13):6455-69. 
65. Yap TA, Yan L, Patnaik A, Fearen I, Olmos D, Papadopoulos K, Baird RD, Delgado L, Taylor A, Lupinacci L, Riisnaes R, Pope LL, Heaton SP, Thomas G, Garrett MD, Sullivan DM, de Bono JS, Tolcher AW (2011) First-in-man clinical trial of the oral pan-AKT inhibitor MK-2206 in patients with advanced solid tumors. J Clin Oncol 29(35):468895.

66. Cox J, Mann M (2008) MaxQuant enables high peptide identification rates, individualized p.p.b.-range mass accuracies and proteome-wide protein quantification. Nat Biotechnol 26(12):1367-72.

67. Chen Z-L, Meng J-M, Cao Y, Yin J-L, Fang R-Q, Fan S-B, Liu C, Zeng W-F, Ding Y-H, Tan D, Wu L, Zhou W-J, Chi H, Sun R-X, Dong M-Q, He S-M (2019) A high-speed search engine pLink 2 with systematic evaluation for proteome-scale identification of crosslinked peptides. Nat Commun 10(1):3404.

68. Perez-Riverol Y, et al. (2019) The PRIDE database and related tools and resources in 2019: improving support for quantification data. Nucleic Acids Res 47(D1):D442D450.

69. Stariha JTB, Hoffmann RM, Hamelin DJ, Burke JE (2021) Probing Protein-Membrane Interactions and Dynamics Using Hydrogen-Deuterium Exchange Mass Spectrometry (HDX-MS). Methods Mol Biol 2263:465-485.

70. Dobbs JM, Jenkins ML, Burke JE (2020) Escherichia coli and Sf9 Contaminant Databases to Increase Efficiency of Tandem Mass Spectrometry Peptide Identification in Structural Mass Spectrometry Experiments. J Am Soc Mass Spectrom 
31(10):2202-2209.

71. Masson GR, et al. (2019) Recommendations for performing, interpreting and reporting hydrogen deuterium exchange mass spectrometry (HDX-MS) experiments. Nat Methods 16(7):595-602.

72. Petoukhov M V., Konarev P V., Kikhney AG, Svergun DI, IUCr (2007) ATSAS 2.1 towards automated and web-supported small-angle scattering data analysis. J Appl Crystallogr 40(s1):s223-s228. 


\section{Figure Legends}

Figure 1. A transient, but specific dimer controls PDK1 autophosphorylation.

(A) Size exclusion chromatography coupled to multi-angle light scattering (SEC-MALS) of PDK1FL S241A (green) and PDK1 SKD S241A (black). The table summarizes protein polydispersity, theoretical $\left(\mathrm{Mr}_{\text {theor }}\right)$ and experimentally determined $\left(\mathrm{Mr}_{\exp }\right)$ molecular weights, as well as the calculated oligomeric state $\left(\mathrm{Mr}_{\mathrm{exp}} / \mathrm{Mr}_{\text {theor }}\right)$.

(B) Model of the PDK1 kinase domain dimer obtained using the ROSETTA symmetric modeling tool. Kinase domains (PDB: 2biy) are shown in dark and light grey. Activation loop residues 228-245 that were removed from the structure for the purpose of modeling are shown in dashed blue lines. The hydrophobic motif of PRK2 (PIFtide) bound to the hydrophobic pocket (PDB: 4rrv) is depicted with a black line. Y288 in the dimer interface is highlighted in red.

(C) Radiometric PDK1 autophosphorylation assay. PDK1 SKD (closed black squares), PDK1 ${ }^{\text {SKD }}$ Y288A (closed red diamonds) and PDK1 ${ }^{\text {SKD }}$ Y288E (closed blue circles). Error bars are the standard deviation of three independent experiments.

\section{Figure 2. PIF pocket occupancy promotes PDK1 trans-autophosphorylation.}

(A) Graphical schematics of PDK1 ${ }^{\text {SKD-PIF }}$ and PDK1 ${ }^{\text {PIF-SKD }}$ fusion proteins. PIFtide is

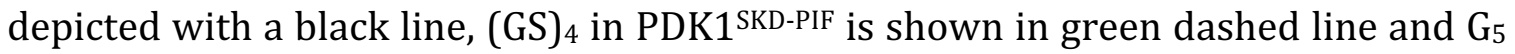
linker in PDK1 ${ }^{\text {PIF-SKD }}$ is shown in red dashed line. Activation loops that were removed from the structure are shown in dark blue dashed lines. 
(B) Size exclusion chromatography coupled to multi-angle light scattering (SEC-MALS) of PDK1 SKD-PIF S241A run in the presence (light green) or absence (dark green) of $1 \mathrm{mM}$ ATP and PDK1 1 PIF-SKD S241A run in the presence (light red) or absence (dark red) of 1 mM ATP. The table summarizes protein polydispersity, theoretical $\left(\mathrm{Mr}_{\text {theor }}\right)$ and experimentally determined $\left(\mathrm{Mr}_{\mathrm{exp}}\right)$ molecular weights, as well as the calculated oligomeric state $\left(\mathrm{Mr}_{\mathrm{exp}} / \mathrm{Mr}_{\text {theor }}\right)$.

(C) Radiometric autophosphorylation assay. PDK1 1 SKD (closed black squares) and PDK1 ${ }^{\text {PIF-SKD }}$ (open red diamond). Error bars are the standard deviation of three independent experiments.

(D) Cross-linking mass spectrometry analysis of PDK1 $1^{\text {SKD-PIF }}$ S241A in the presence of ATP. EDC crosslinked peptides are mapped on the model of the kinase domain. Monomer-specific crosslinks are shown in purple, dimer-specific crosslinks are shown in cyan. The activation loop is highlighted in blue.

(E) - (H) Comparison of deuterium incorporation in the PDK1 monomer (PDK1 ${ }^{\mathrm{SKD}}$ ) and dimer (PDK1 ${ }^{\text {SKD-PIF }) . ~ P I F t i d e ~ i s ~ d e p i c t e d ~ w i t h ~ a ~ s o l i d ~ b l a c k ~ l i n e, ~ t h e ~}(\mathrm{GS})_{4}$ linker in dashed line. The activation loop is shown in red mesh representation. The sequence below the model (in cyan) is the sequence of the activation loop that was removed for modeling. Peptides showing significant deuterium exchange differences were mapped on the PDK1 kinase domain dimer model. Color code for the magnitude of changes in deuterium incorporation is shown to the bottom right of panel $\mathrm{H}$. 
Figure 3. A hydrophobic motif in PDK1 drives trans-autophosphorylation.

(A) Alignment of the kinase-PH interdomain linker of chordate PDK1 orthologs. Below: schematic of the PDK1 ${ }^{\text {SKD }}$ and PDK1 ${ }^{\mathrm{LKD}}$ constructs with relative positions of the 'NYD' and hydrophobic $(\Phi \times x \Phi)$ motifs.

(B) Radiometric autophosphorylation assay. PDK1 SKD (closed black squares) and PDK1 ${ }^{\mathrm{LKD}}$ (closed blue triangles). Error bars are the standard deviation of three independent experiments.

(C) Size exclusion chromatography coupled to multi-angle light scattering (SEC-MALS) of PDK1LKD S241A in the presence of $1 \mathrm{mM}$ ATP. The table summarizes protein polydispersity, theoretical $\left(\mathrm{Mr}_{\text {theor }}\right)$ and experimentally determined $\left(\mathrm{Mr}_{\mathrm{exp}}\right)$ molecular weights, as well as the calculated oligomeric state $\left(\mathrm{Mr}_{\mathrm{exp}} / \mathrm{Mr}_{\text {theor }}\right)$.

(D) Radiometric autophosphorylation assay. PDK1 ${ }^{\text {LKD }}$ (closed blue triangles), PDK1 PIF-LKD (open black circles) and PDK1 1 PIF-SKD (open red diamonds). Error bars are the standard deviation of three independent experiments.

(E) Radiometric autophosphorylation assay. PDK1 LKD (closed blue triangles), PDK1 $1^{\mathrm{LKD}}$ F383A/M386A (closed red circles) and PDK1 ${ }^{\text {SKD }}$ (closed black squares). Error bars are the standard deviation of three independent experiments (red asterisk indicates removal of one outlier).

(F) Radiometric autophosphorylation assay. PDK1 LKD (closed blue triangles) and PDK1LKD Y376A (closed red squares). Error bars are the standard deviation of three independent experiments. 


\section{Figure 4. PDK1 is autoinhibited by its PH domain.}

(A) Radiometric autophosphorylation assay. PDK1 ${ }^{\text {SKD }}$ (closed black squares), PDK1 LKD (closed blue triangles) and PDK1 ${ }^{\mathrm{FL}}$ (closed green circles). Error bars are the standard deviation of three independent experiments.

(B) Comparison of deuterium incorporation between PDK1 $1^{\mathrm{FL}}$ and PDK1 ${ }^{\mathrm{SKD}}$ in solution. Peptides showing significant deuterium exchange differences were mapped on the PDK1 kinase domain structure (pdb code: 2biy). Color code for the magnitude of changes in deuterium incorporation is shown on the right.

(C) Comparison of deuterium incorporation between PDK1 ${ }^{\mathrm{FL}}$ and PDK1 ${ }^{\mathrm{PH}}$. Peptides showing significant deuterium exchange differences were mapped on the PDK1 PH domain structure (PDB: 1w1d). Color coding is the same as in Figure 4B.

(D) Binding of PDK1 $1^{\mathrm{FL}}$ and $\mathrm{PDK} 1^{\mathrm{PH}}$ to $0-2 \mathrm{~mol} \% \mathrm{PIP}_{3}$ liposomes. Error bars are the standard deviation of three independent experiments. Data were fit with a HillLangmuir isotherm in which no parameters were constrained. The equilibrium dissociation constants derived from curve fitting, together with the respective Hill coefficients, are reported in the table (inset).

(E) Schematic of the conformational changes associated with $\mathrm{PIP}_{3}$ binding that give rise to the positive cooperativity in binding.

(F) Small-angle X-ray scattering (SAXS) curves for S241-monophosphorylated (black) and dephosphorylated (red) PDK1 ${ }^{\mathrm{FL}}$ in solution.

(G) Normalized residuals plot comparing the scattering curves of S241monophosphorylated and dephosphorylated PDK1 $1^{\mathrm{FL}}$. 
(H)Guinier plot of the solution scattering data for S241 mono-phosphorylated (black) and dephosphorylated (red) PDK1 ${ }^{\mathrm{FL}}$. The interval of $0.32<\mathrm{qRg}<1.29$ was used to determine the radius of gyration $\left(\mathrm{R}_{\mathrm{g}}\right)$ by linear regression of $\ln \mathrm{I}(\mathrm{q})$ versus $\mathrm{q}^{2}$.

(I) Residuals plots for the Guinier fits of S241-monophosphorylated (black) and dephosphorylated (red) PDK1 FL.

(J) Pair distribution functions for S241-monophosphorylated (black) and dephosphorylated PDK1 ${ }^{\mathrm{FL}}$ (red) with $\mathrm{R}_{\mathrm{g}}$ and maximum particle dimension $\left(\mathrm{D}_{\max }\right)$ derived from it.

(K) $A b$ initio calculation of the molecular envelope of PDK1 ${ }^{\mathrm{FL}}$.

Figure 5. Model of phosphoinositide-driven PDK1 activation.

Cytosolic PDK1 is inhibited by its $\mathrm{PH}$ domain. $\mathrm{PIP}_{3}$ binding relieves autoinhibition by displacing the PH domain from the dimerization surface and catalytic cleft of the kinase domain. Dimerization of the PH domain upon $\mathrm{PIP}_{3}$ binding leads to PDK1 kinase domain dimerization, inter-domain linker exchange (which includes the specific binding of NFD and hydrophobic motifs), and trans-autophosphorylation of the activation loop on S241. Upon trans-autophosphorylation, the phosphorylated kinase domain dimer dissociates, rendering it competent to bind and phosphorylate downstream substrate kinases. The substrate kinase Akt is used to illustrate the final step in PDK1-mediated downstream kinase activation (far right). 
Figure 1. A transient, but specific dimer controls PDK1 autophosphorylation.

bioRxiv preprint doi: https://doi.org/10.1101/2021.10.08.463254; this version posted October 8, 2021. The copyright holder for this preprint (which was not certified by peer review) is the author/funder, who has granted bioRxiv a license to display the preprint in perpetuity. It is made

A

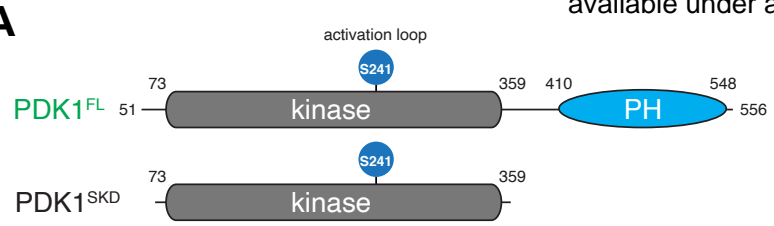

B

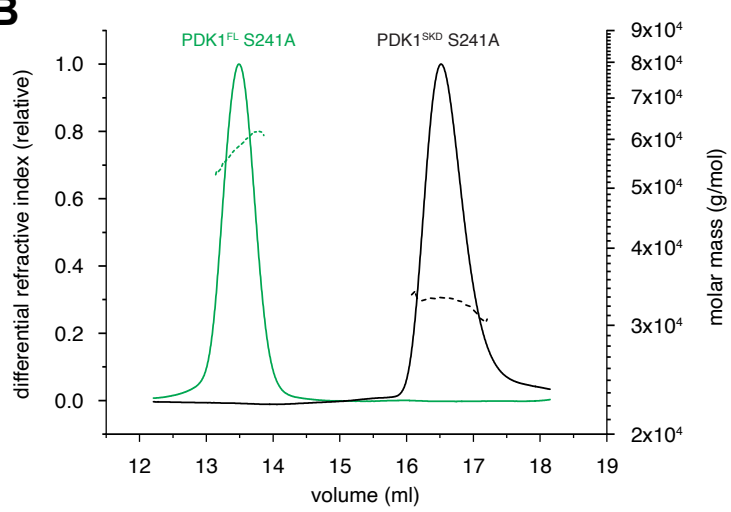

C-BY 4.0 International license.

\begin{tabular}{|l|c|c|c|c|c|}
\hline Protein & ATP & Polydispersity & $\mathrm{Mr}_{\text {exp }}(\mathrm{kDa})$ & $\mathrm{Mr}_{\text {theor }}(\mathrm{kDa})$ & $\mathrm{Mr}_{\text {exp }} / \mathrm{Mr}_{\text {theor }}$ \\
\hline PDK1 ${ }^{\text {SKD }}$ S241A & + & 1.000 & 33.1 & 33.3 & 0.99 \\
\hline PDK1 $^{\text {FL }}$ S241 A & + & 1.002 & 59.6 & 59.2 & 1.01 \\
\hline
\end{tabular}

D
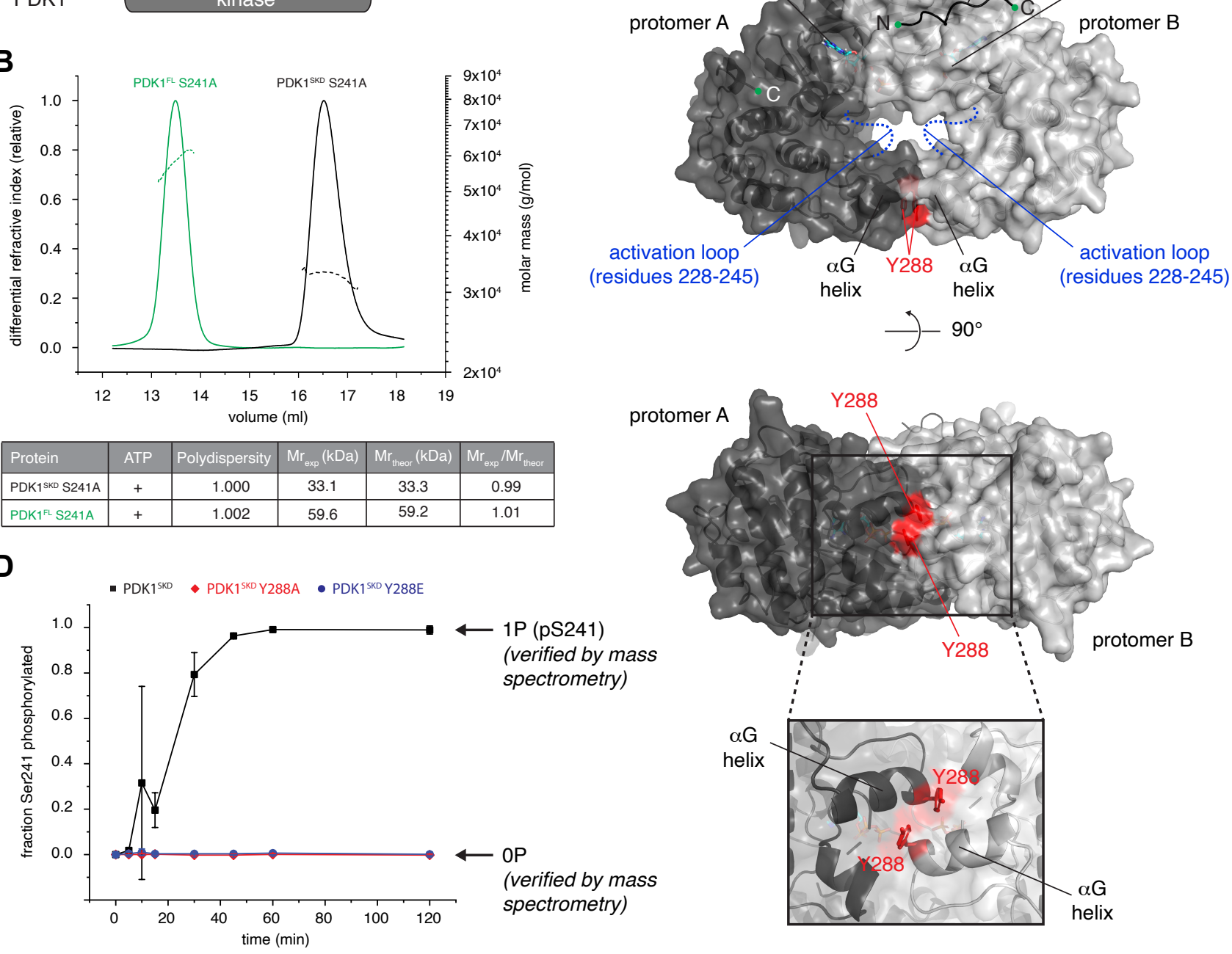

(residues 228-245)

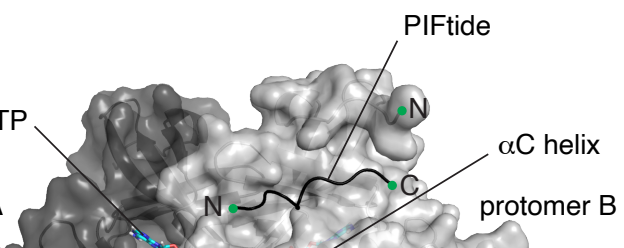

protomer A

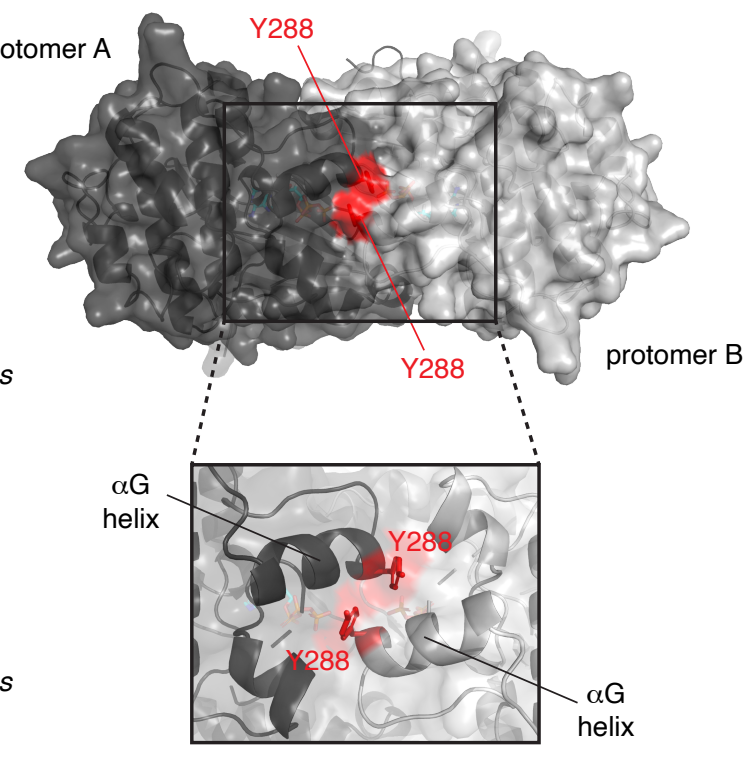




\section{Figure 2. PIF pocket occupancy promotes PDK1 trans-autophosphorylation.}

bioRxiv preprint doi: https://doi.org/10.1101/2021.10.08.463254; this version posted October 8, 2021. The copyright holder for this preprint (which was not certified by peer review) is the author/funder, who has granted bioRxiv a license to display the preprint in perpetuity. It is made

A
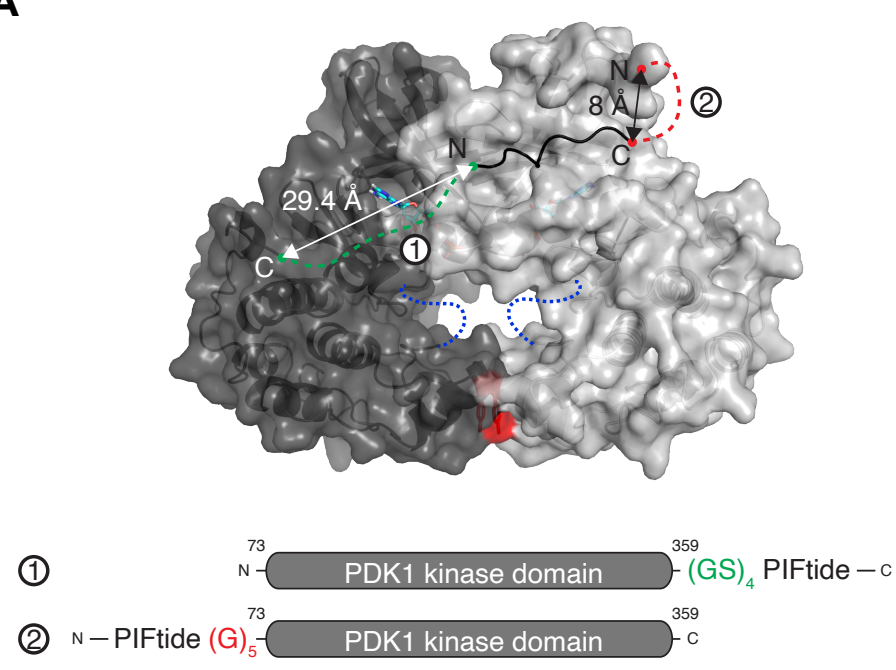

C

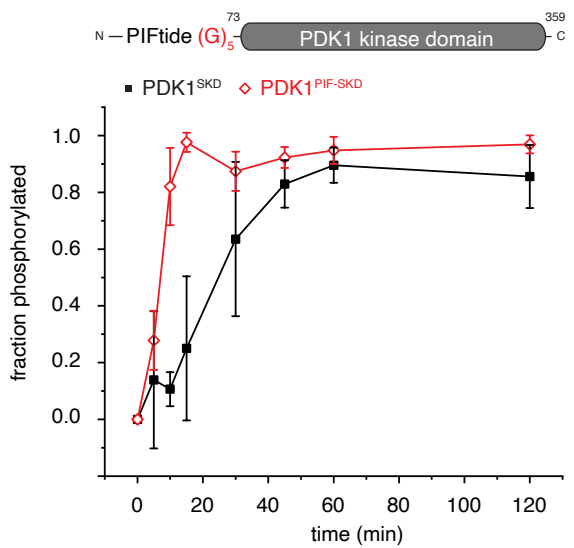

E

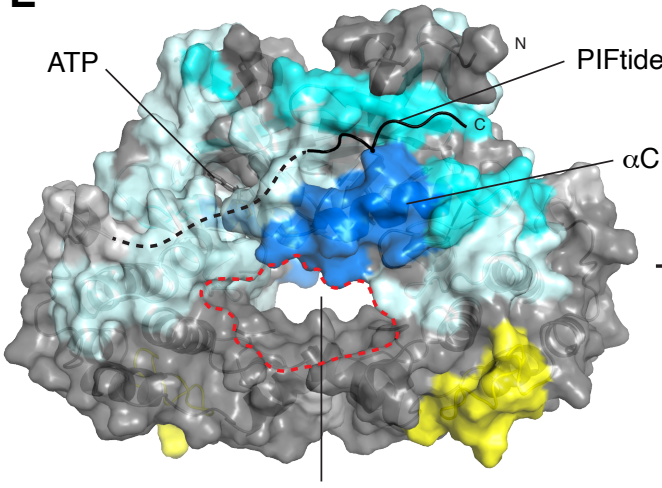

activation loops (x2)

${ }^{223}$ DFGTAKVLSPESKQARANAFVGT 245

G

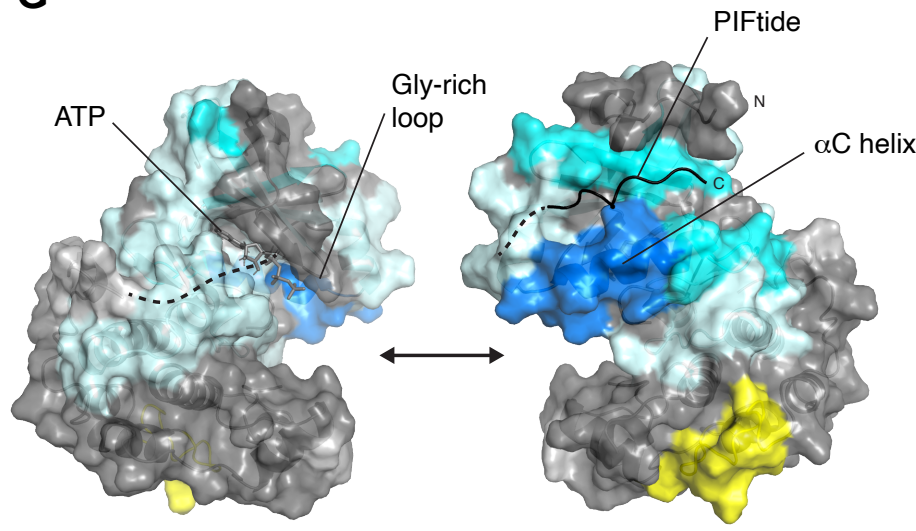

protomer A

D

F
$B^{\text {International license. }}$

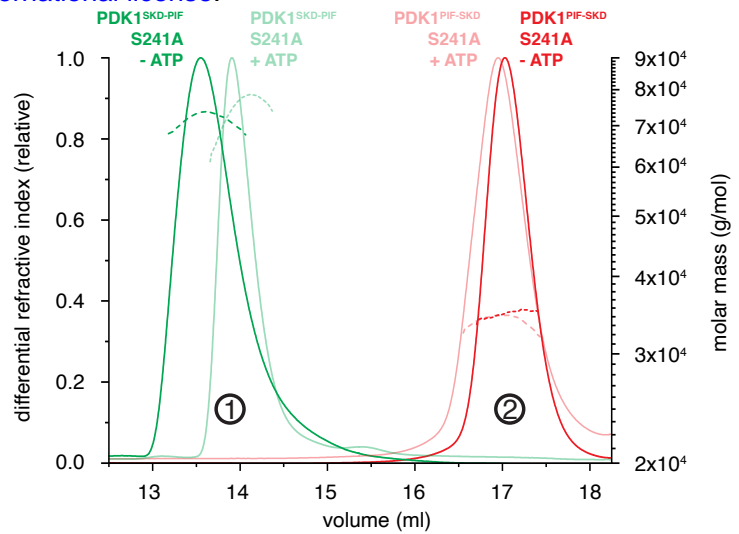

\begin{tabular}{|c|c|c|c|c|c|}
\hline Protein & ATP & Polydispersity & $\mathrm{Mr}_{\text {exp }}(\mathrm{kDa})$ & $\mathrm{Mr}_{\text {theor }}(\mathrm{kDa})$ & $\mathrm{Mr}_{\text {exp }} / \mathrm{Mr}_{\text {theor }}$ \\
\hline PDK1 $1^{\text {PIF-SKD }} \mathrm{S} 241 \mathrm{~A}$ & - & 1.000 & 34.8 & 35.0 & 0.99 \\
\hline PDK1 1PF-SKD S241A & + & 1.000 & 34.1 & 35.0 & 0.97 \\
\hline PDK1 1 אKD-PIF S241A & - & 1.001 & 71.8 & 35.6 & 2.01 \\
\hline PDK1 1 SKD-PIF S241A & + & 1.004 & 74.4 & 35.6 & 2.08 \\
\hline
\end{tabular}
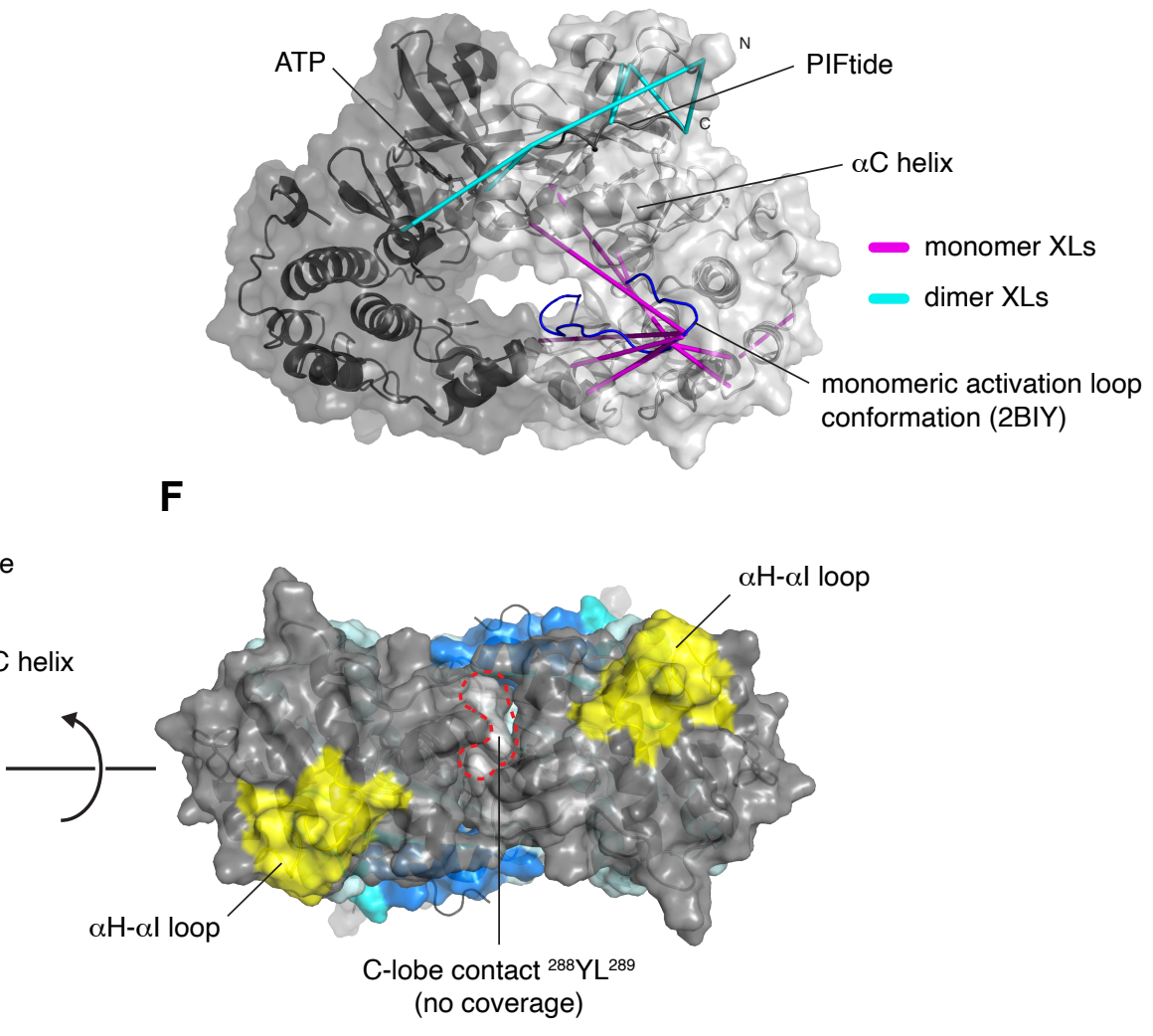

H

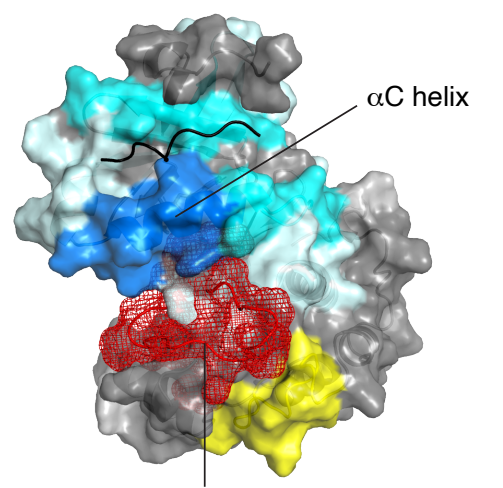

$>25 \%$ protection

$15-25 \%$ protection

4-15\% protection

4-15\% exposure

no change

no coverage

.... (GS) ${ }_{4}$ linker

- PIFtide 


\section{Figure 3. A hydrophobic motif in PDK1 drives trans-autophosphorylation.}

bioRxiv preprint doi: https://doi.org/10.1101/2021.10.08.463254; this version posted October 8, 2021. The copyright holder for this preprint (which was not certified by peer review) is the author/funder, who has granted bioRxiv a license to display the preprint in perpetuity. It is made

A

kinase domain available under aCC-BY 4.0 International license.

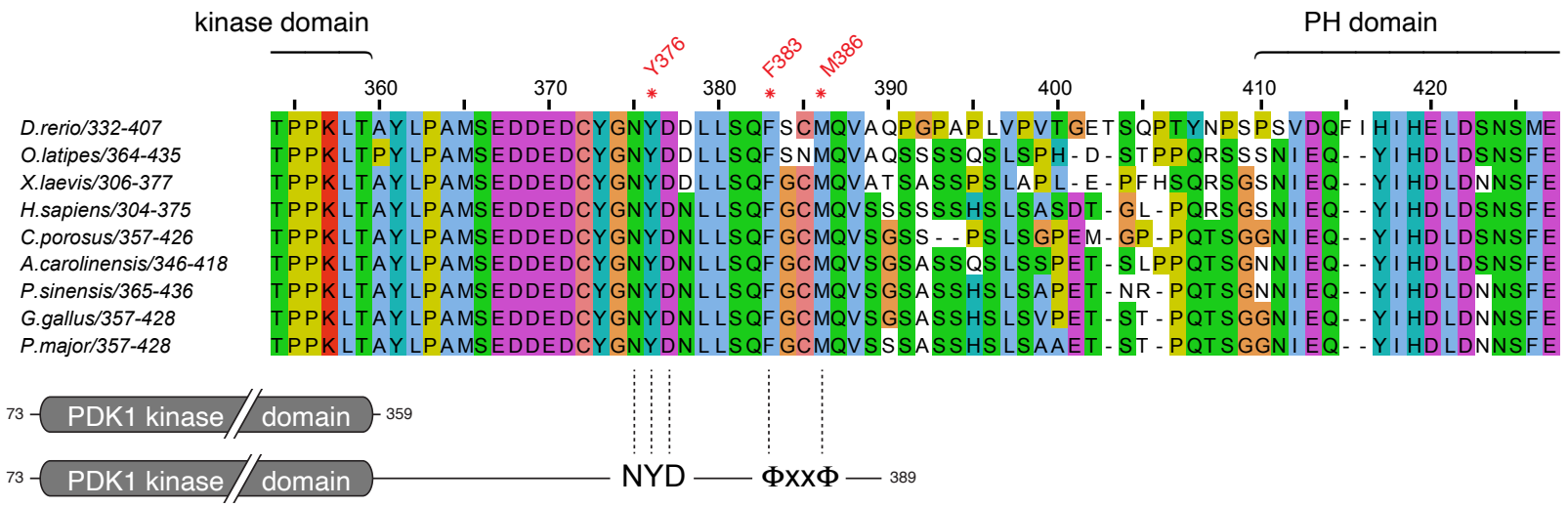

B

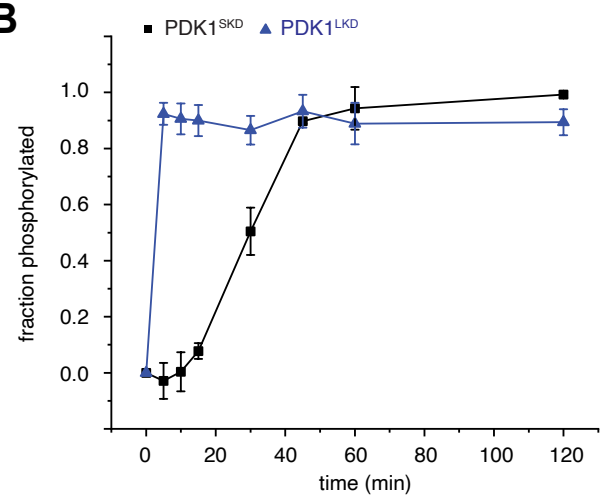

D

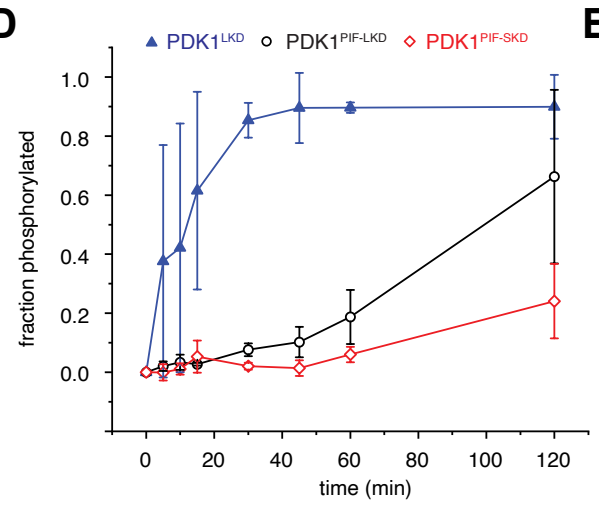

C

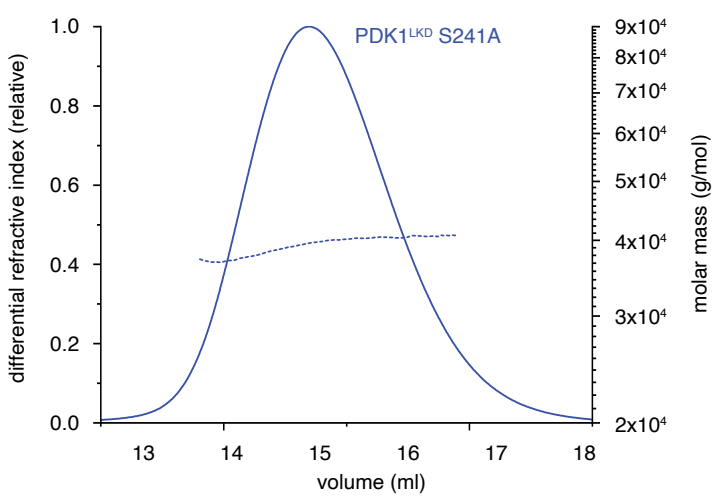

\begin{tabular}{|l|c|c|c|c|c|}
\hline Protein & ATP & Polydispersity & $\mathrm{Mr}_{\text {exp }}(\mathrm{kDa})$ & $\mathrm{Mr}_{\text {theor }}(\mathrm{kDa})$ & $\mathrm{Mr}_{\text {exp }} / \mathrm{Mr}_{\text {theor }}$ \\
\hline PDK1 $^{\text {LKD }}$ S241A & + & 1.001 & 39.4 & 38.8 & 1.02 \\
\hline
\end{tabular}

E
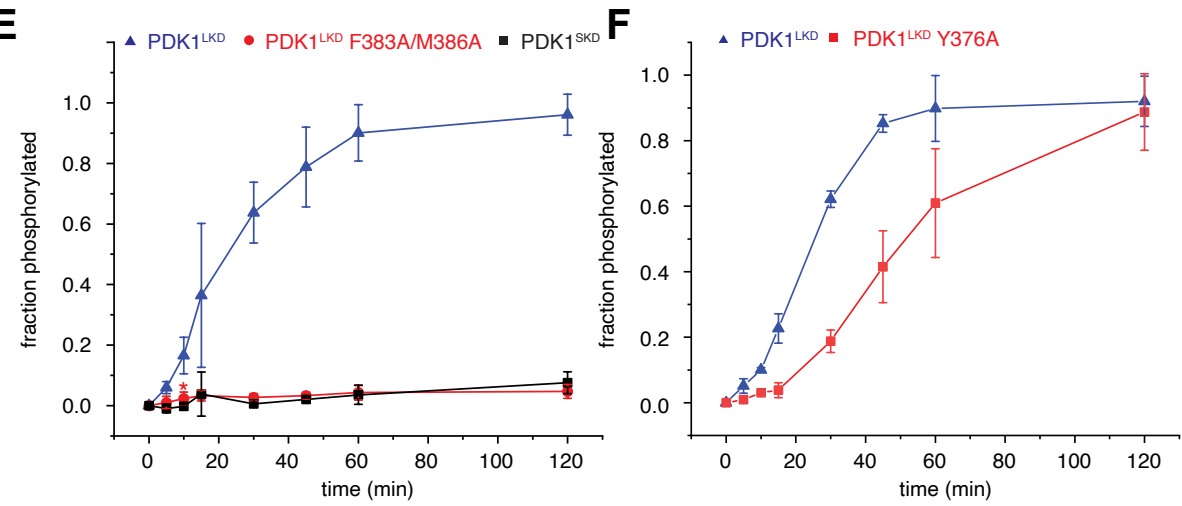
Figure 4. PDK1 is autoinhibited by its PH domain.

bioRxiv preprint doi: https://doi.org/10.1101/2021.10.08.463254; this version posted October 8, 2021. The copyright holder for this preprint (which was not certified by peer review) is the author/funder, who has granted bioRxiv a license to display the preprint in perpetuity. It is made

A

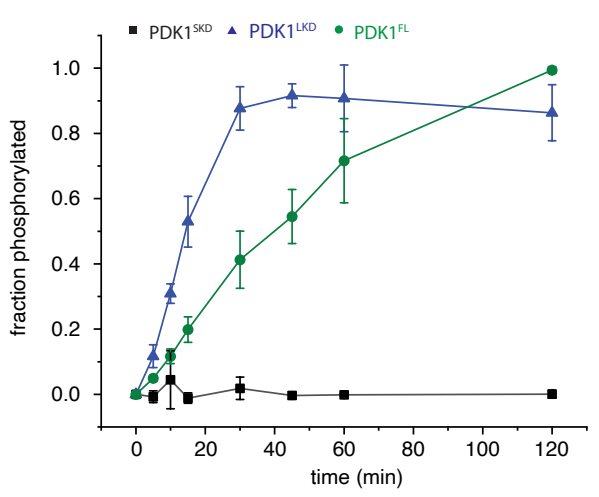

C

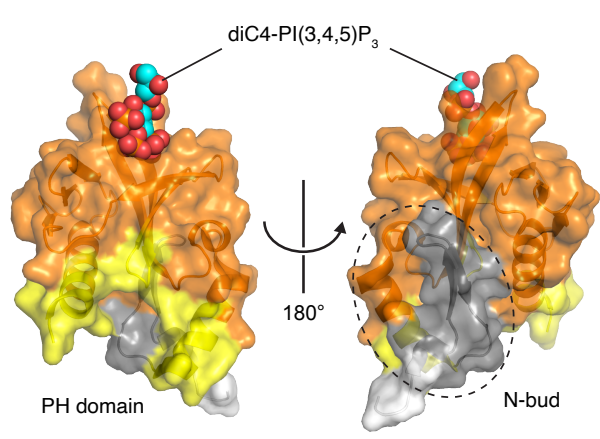

$\mathbf{F}$

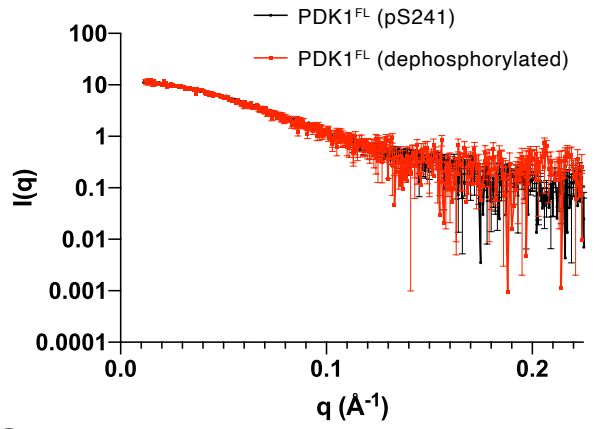

G

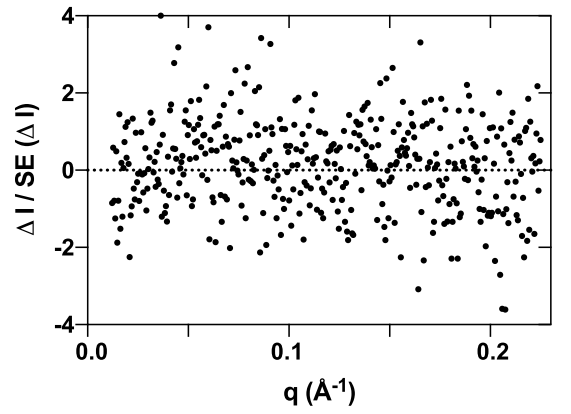

Bun

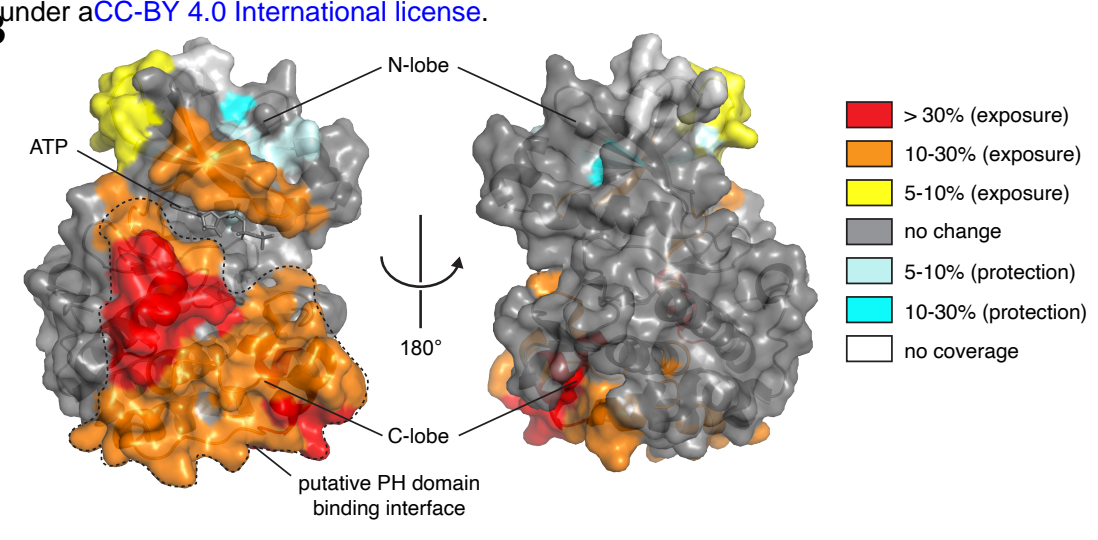

D

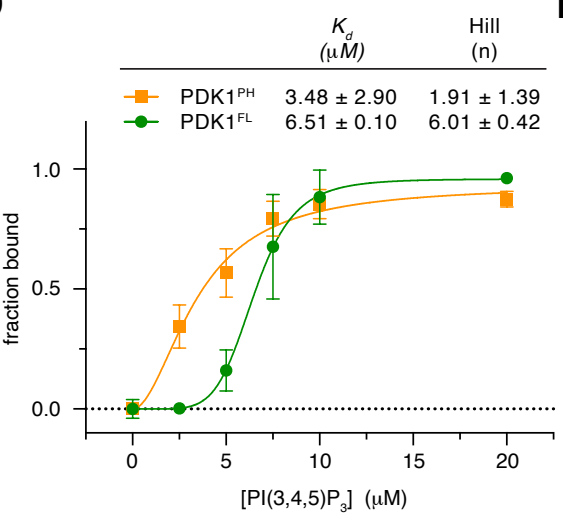

H

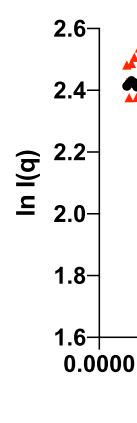

I

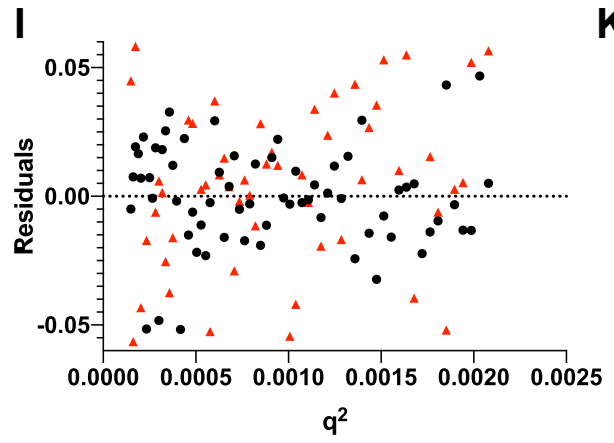

E

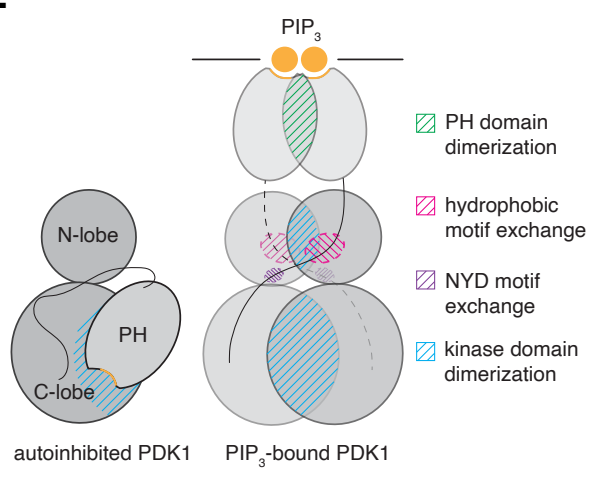

J

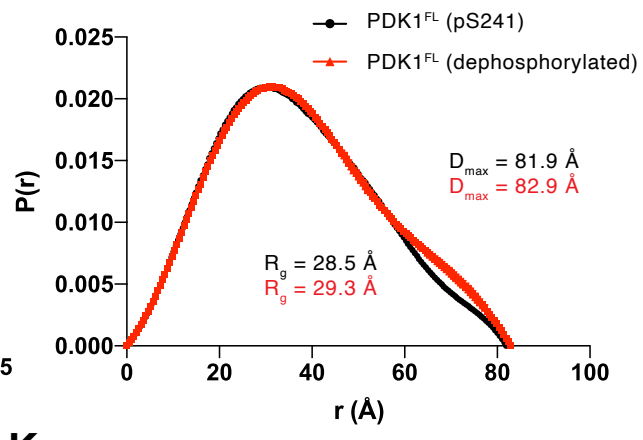

K ab initio molecular envelope

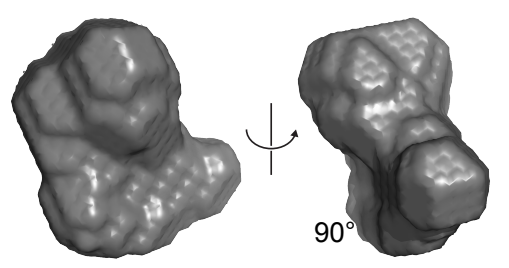


Figure 5. Model of phosphoinositide-driven PDK1 activation.

bioRxiv preprint doi: https://doi.org/10.1101/2021.10.08.463254; this version posted October 8, 2021. The copyright holder for this preprint (which was not certified by peer review) is the author/funder, who has granted bioRxiv a license to display the preprint in perpetuity. It is made

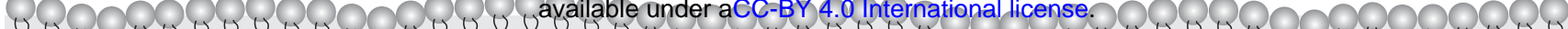

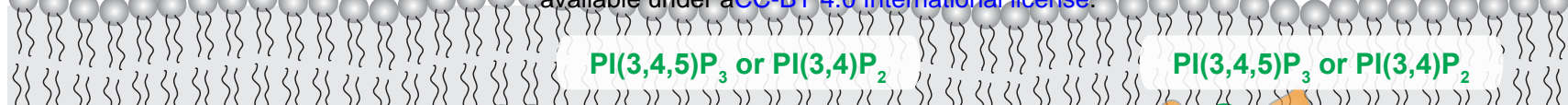

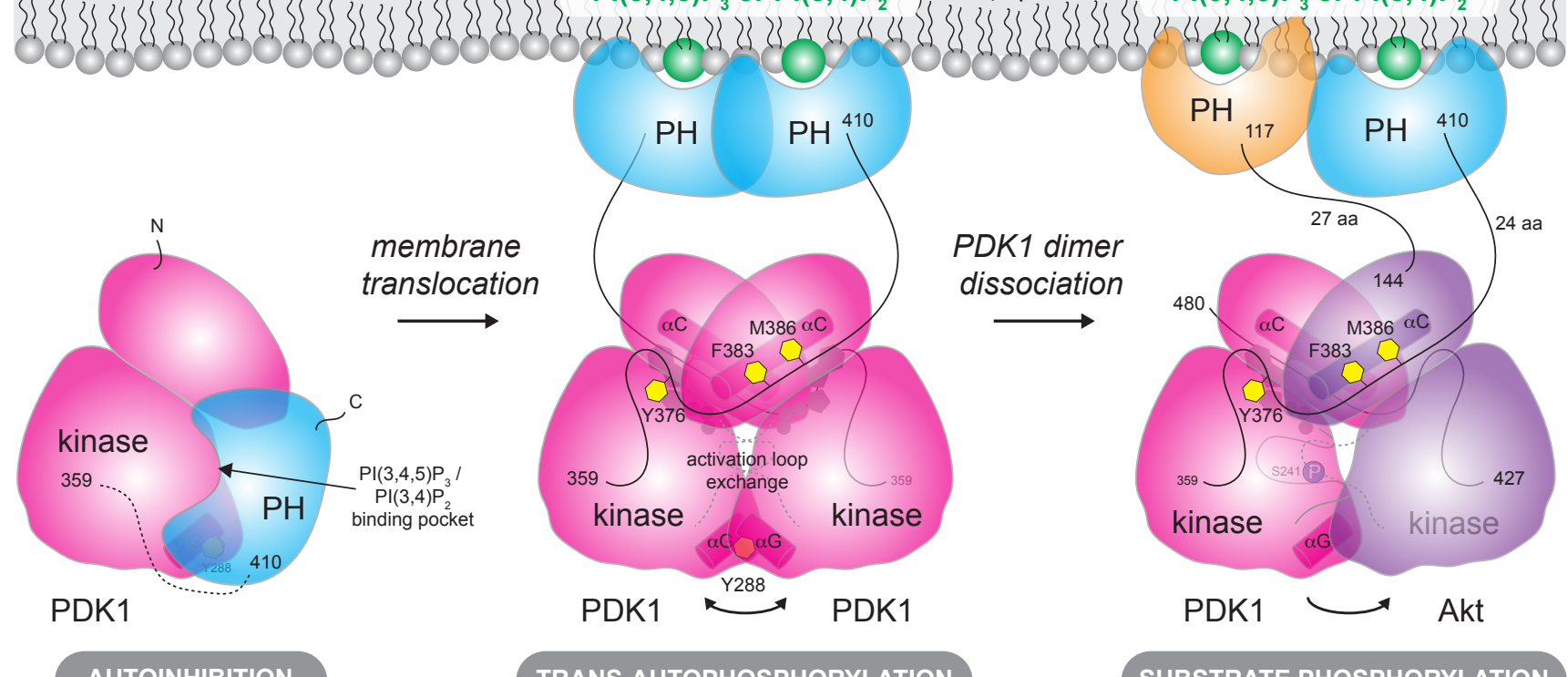

